PONTIFÍCIA UNIVERSIDADE CATÓLICA DO RIO DE JANEIRO

\title{
A influência da sustentabilidade na decisão de compra do consumidor Setor de cosméticos
}

Camilla de Oliveira Silva

Trabalho de Conclusão de CuRso

Centro de CIÊnCIAS SOCIAIS - CCS

DEPARTAMENTO DE AdMINISTRAÇÃO

Graduação em Administração de Empresas 

R IO

\section{Camilla de Oliveira Silva}

\section{A influência da sustentabilidade na decisão de compra do consumidor \\ Setor de cosméticos}

Trabalho de Conclusão de Curso

Trabalho de Conclusão de Curso, apresentado ao programa de graduação em Administração da PUC-Rio como requisito parcial para a obtenção do titulo de graduação em Administração.

Orientador(a) : Sylvia Moraes

Rio de Janeiro, Junho de 2018. 


\section{Agradecimentos}

Agradeço primeiramente a Deus por ter guiado o meu caminho e aos meus pais por todo amor, apoio e por terem me dado a oportunidade de estudar na PUC-Rio.

A professora Sylvia Moraes por ter aceitado me orientar na elaboração deste trabalho, estando sempre disposta a me ajudar.

Aos meus familiares e amigos por todo apoio, motivação e incentivo. 


\section{Resumo}

Silva, O. Camilla. A influência da sustentabilidade na decisão de compra do consumidor no setor de cosméticos. Rio de Janeiro, 2018. 60 p. Trabalho de Conclusão de Curso - Departamento de Administração. Pontifícia Universidade Católica do Rio de Janeiro.

Este trabalho foi realizado com o objetivo de entender melhor e averiguar a influência da sustentabilidade na decisão de compra dos consumidores por produtos cosméticos sustentáveis. O estudou buscou compreender se iniciativas de sustentabilidade do setor de cosméticos são valorizadas pelos consumidores e também os motivos que levam os consumidores a comprarem produtos cosméticos sustentáveis, assim como as barreiras a compra deste tipo de produto. O método empregado foi o quantitativo por meio da aplicação de um questionário desenvolvido pela autora que abordaram questões referentes ao comportamento de consumo em relação aos cosméticos e questões abordando a sustentabilidade relacionada a cosméticos. A conclusão da pesquisa aponta que a sustentabilidade influencia os consumidores, contudo foi observado no estudo que não é o único fator de decisão de compra. Os consumidores ainda são muito influenciados pela qualidade dos produtos cosméticos e pelo seu valor final. O preço elevado dos produtos sustentáveis e a falta de informação em relação a este tipo de produto foram apontados como as principais barreiras.

Palavras- chave: Sustentabilidade; cosméticos; produtos sustentáveis 


\begin{abstract}
Silva, O. Camilla. The influency of sustainability on the consumers purchase decision in the cosmetic industry. Rio de Janeiro, 2018. 60 p. Trabalho de Conclusão de Curso - Departamento de Administração. Pontifícia Universidade Católica do Rio de Janeiro.
\end{abstract}

This study had the objective to understand the influency of sustainability on the consumers purchase decision related to sustainable cosmetics. The purpose of this study was to comprehend if sustainability iniciatives in the cosmetic industry are valued by the consumers and also to understand the consumers main reasons to purchase sustainable cosmetics as well as the barriers to purchase such products. The research was made through a quantitative questionnaire developed by the author of the study, which approached questions regarding the consumers behavior related to cosmetics and the sustainability related to cosmetics. The conclusion of the research pointed that sustainability influences the consumers, however it was observed in the study that there are other reasons that may affect the consumers purchase decision. The majority of the consumers are still influenced by the quality of the cosmetics products and by the price. The high price of the sustainable products and the lack of information related to these products were pointed by the consumers as the main barriers to purchase such products.

Key words: sustainability; cosmetics; sustainable products 


\section{Sumário}

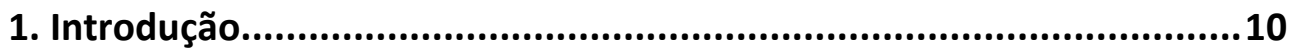

1.1. Introdução ao tema e ao problema do estudo .......................................10

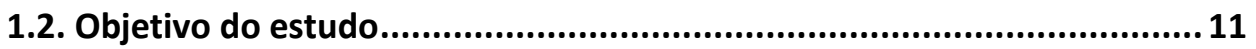

1.3. Objetivos intermediários do estudo..................................................... 11

1.4. Delimitação e foco do estudo ................................................................. 12

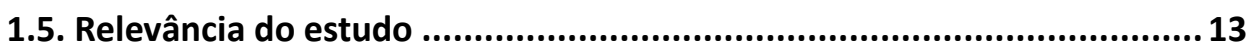

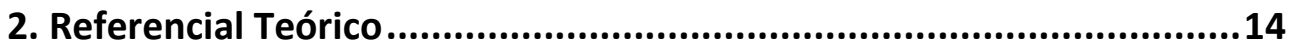

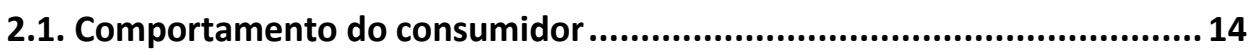

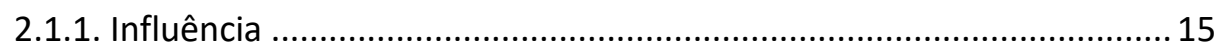

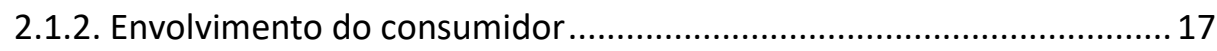

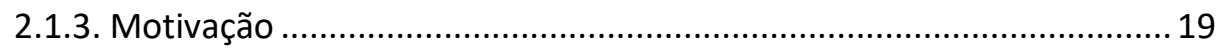

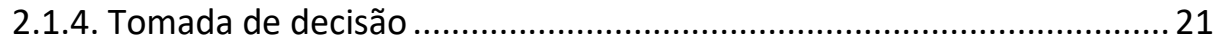

2.2. Responsabilidade social.................................................................22

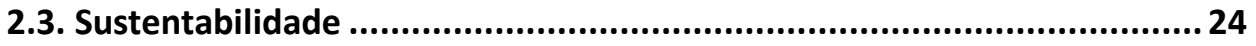

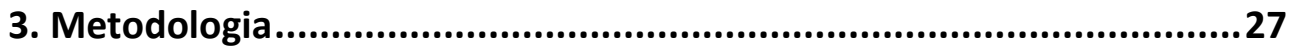

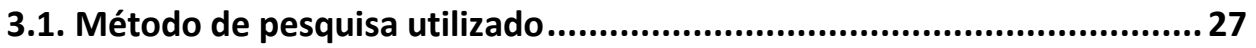

3.2. Fontes de informação selecionadas para coletas de dados no estudo .... 27

3.3. Procedimentos e instrumentos de coleta de dados utilizados no estudo 28

3.4. Formas de tratamento e análise dos dados coletados para o estudo...... 29

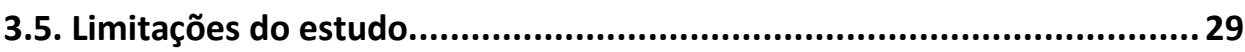

4. Apresentação e análise dos resultados..........................................30

4.1. Descrição dos resultados sociodemográficos ...........................................30

4.2. Comportamento do consumo de cosméticos.........................................31

4.3. Sustentabilidade associada ao consumo de cosméticos ..........................36

4.4. Motivações e barreiras para a compra de cosméticos sustentáveis ........ 45

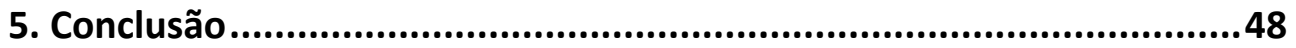

5.1. Sugestões e recomendações para novos estudos....................................50

6. Referências Bibliográficas .......................................................51

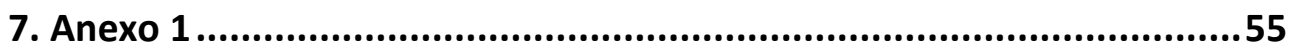




\section{Índice de Figuras}

Figura 1 - Respostas às assertivas sobre consumo de cosméticos................... 36

Figura 2 - Respostas às assertivas sobre iniciativas de sustentabilidade .......... 45 


\section{Índice de Tabelas}

Tabela 1 - Resumo das variáveis da pesquisa ............................................. 28

Tabela 2 - Perfil sociodemográfico dos respondentes .................................... 31

Tabela 3 - Respostas à pergunta sobre sustentabilidade ............................... 36

Tabela 4 - Respostas à pergunta sobre influência dos cosméticos sustentáveis 37

Tabela 5 - Respostas à pergunta sobre compra de cosméticos sustentáveis.... 37

Tabela 6 - Respostas à pergunta sobre cosméticos orgânicos ou naturais ....... 39 


\section{Índice de Gráficos}

Gráfico 1 - Respostas à pergunta sobre compras ...................................... 31

Gráfico 2 - Respostas à pergunta sobre intermediação comercial ..................... 32

Gráfico 3 - Respostas à pergunta sobre marcas utilizadas ............................. 32

Gráfico 4 - Respostas à pergunta sobre critérios de seleção........................... 33

Gráfico 5 - Respostas à pergunta sobre marcas associadas a sustentabilidade 34

Gráfico 6 - Respostas à pergunta sobre associações a marcas de cosméticos. 40

Gráfico 7 - Respostas à pergunta sobre motivos para a compra sustentável .... 46

Gráfico 8 - Respostas à pergunta sobre barreiras a compra sustentável........... 47 


\section{Introdução}

\subsection{Introdução ao tema e ao problema do estudo}

Vem se observando na atualidade uma mudança no comportamento dos consumidores em relação a compra de cosméticos e diante disso, a indústria de cosméticos vem se reformulando, além do menor impacto ambiental, os consumidores vêm buscando produtos mais saudáveis para pele e cabelos, demonstrando predileção por ingredientes naturais, vegetais e embalagens de refil. (O ESTADO DE SÃO PAULO, 2018).

Consumidores estão buscando produtos cosméticos mais saudáveis com menor impacto ambiental e o crescimento de marcas verdes nesse segmento mostra a tendência de mudança. O movimento natural e orgânico fica cada vez mais forte, graças a um consumidor cada vez mais exigente. De acordo com Prata (2017) a maioria dos consumidores verdes tem menos de 30 anos de idade, uma nova geração com novas ideias que demanda novas atitudes das empresas.

Diante disto, a indústria de cosméticos vem passando por alguns desafios como o empenho em tornar seus processos mais verdes e também em envolver os consumidores que ainda não tem muito contato com os produtos verdes.

Ainda segundo Prata (2017) uma pesquisa feita em 2017 pela Euromonitor (provedora global de inteligência estratégica de mercado) concluiu que mais de $40 \%$ dos consumidores do mercado de beleza ainda são muito influenciados pelo custo benefício, contudo, este cenário está começando a mudar globalmente. De acordo com Oliveira (2015) o estudo feito em 2015 pela Organic Monitor (agência desenvolvedora de pesquisas de mercado na área de produtos naturais e orgânicos) apontou que o setor de cosméticos orgânicos movimenta aproximadamente US\$ 9 bilhões em todo o mundo. É previsto que até o ano de 2025 o mercado de produtos de higiene pessoal orgânicos movimente US\$ 25 bilhões, de acordo com a consultoria americana Grand View Research.

Segundo Santos (2017) os consumidores querem empresas preocupadas com o meio ambiente. Na visão de Helio Mattar, presidente do Instituto Akatu (organização que trabalha pela conscientização e mobilização da sociedade para o consumo consciente) as políticas de responsabilidade socioambiental não 
são mais um diferencial para as empresas, mas sim uma obrigação. (SANTOS, 2017).

Contudo, empresas brasileiras ainda estão na contramão no que diz respeito a inovação para diminuir impactos ambientais negativos na produção e amplificar os impactos positivos.

Segundo o Instituto Brasileiro de Defesa da Natureza (2017) empresas com políticas socioambientais não são mais vistas no mercado pelo consumidor como organizações revolucionárias. A cautela com questões ambientais por parte das indústrias passou a ser vista como uma incumbência e como filosofia de negócios.

Diante deste cenário, as empresas precisam cada vez mais se reinventar e se reformular para atrair este consumidor mais envolvido e comprometido com questões ambientais. As empresas devem mostrar seu envolvimento ecológico e ambiental, seja pela maneira como o produto é produzido (cadeia produtiva), vendido ou embalado. As preocupações com o meio ambiente e com a sustentabilidade empresarial estão ganhando cada vez mais força e relevância na atualidade, comprovando o quanto empresas socialmente responsáveis podem exercer influência na tomada de decisão do consumidor na hora da compra.

Empresas preocupadas com medidas a respeito da preservação do meio ambiente podem ter diversas vantagens, entre elas, sua sobrevivência no mercado. Organizações que procuram adotar ações que promovem e incentivam campanhas relacionadas ao cuidado com o meio ambiente são mais bem vistas pelos consumidores.

\subsection{Objetivo do estudo}

Este estudo possui como objetivo entender melhor e averiguar a influência da sustentabilidade na decisão de compra dos consumidores por produtos cosméticos sustentáveis. O estudo buscará compreender se iniciativas de sustentabilidade do referido setor são valorizadas pelos consumidores.

\subsection{Objetivos intermediários do estudo}

$\mathrm{Na}$ intenção de alcançar o objetivo final do problema de estudo em questão, alguns objetivos intermediários foram traçados, como: 
- Averiguar se o fato do produto ser sustentável é um diferencial para os consumidores na decisão de compra.

- Identificar quais iniciativas de sustentabilidade são valorizadas pelos consumidores.

- Identificar os motivos que levam os consumidores a comprarem produtos sustentáveis.

- Identificar os fatores que podem influenciar negativamente os consumidores na compra de produtos sustentáveis.

Através dos objetivos intermediários será possível entender se as iniciativas de sustentabilidade influenciam a decisão de compra dos consumidores.

\subsection{Delimitação e foco do estudo}

O estudo será delimitado ao setor de cosméticos, abrangendo cremes para rosto/pele, perfumes e maquiagens. Atualmente, o setor de cosméticos orgânicos e naturais vem movimentando muito o mercado global e cada vez mais as pessoas estão na busca de um estilo de vida mais saudável e natural, o que vem aumentando a procura por estes produtos. O setor de cosméticos está cada vez mais no caminho da sustentabilidade, seja nos processos de fabricação ou na comercialização dos produtos, razão pela qual o estudo será limitado a este setor em detrimento de outros.

O foco do estudo será nos consumidores de cosméticos homens e mulheres, brasileiros e residentes majoritariamente do Rio de Janeiro. O estudo também tem como foco abordar o conceito de sustentabilidade no geral, não especificando ou detalhando assuntos referentes ao tema, como empresas que não testam em animais ou os hábitos de consumo de produtos cosméticos naturais ou orgânicos.

Sendo assim, o estudo buscará compreender se a sustentabilidade influencia na tomada de decisão do consumidor e se iniciativas e ações sustentáveis feitas pelas empresas do setor de cosméticos são valorizadas. 


\subsection{Relevância do estudo}

Os resultados obtidos pelo estudo podem ajudar as empresas do setor de cosméticos a avaliarem de uma melhor forma suas estratégias, práticas e iniciativas em relação a sustentabilidade e se de fato estas ações influenciam e são valorizadas pelos consumidores. As marcas podem ter um melhor entendimento sobre o comportamento do consumidor em relação aos seus produtos e suas ações sustentáveis. As informações deste estudo também podem ajudar e servir de exemplo para as empresas do setor de cosméticos em uma escala global.

De acordo com Piva (2017) a estimativa é de que foram gastos em 2015 cerca de US\$ 10 bilhões no mundo (aproximadamente $R \$ 31$ bilhões) em produtos orgânicos relacionados ao cuidado pessoal. Atualmente, os principais mercados e mais promissores para cosméticos orgânicos estão na América do Norte (35\%) e Europa (24\%).

Países como o Brasil, a China e a Índia são vistos como mercados com grande potencial para a comercialização de produtos orgânicos (cosméticos, produtos para o cabelo, para a pele e higiene bucal). $\mathrm{O}$ comércio de cosméticos orgânicos atinge diversos segmentos da população, que buscam nestes produtos uma melhor qualidade de vida ou ainda evitar e se preservar do uso de produtos químicos.

Conforme pesquisa feita em 13 países pela Environment Research, realizada pela Tetra Pak no ano de 2017, 95\% dos brasileiros creem que as questões relacionadas ao meio ambiente e a sustentabilidade devem ganhar ainda mais espaço nos próximos anos. Contudo, segundo a pesquisa, existem algumas barreiras para os consumidores em relação a compra de produtos verdes, algumas dessas barreiras são: 0 alto custo dos produtos ambientalmente responsáveis, a falta de informações sobre os produtos e também a baixa disponibilidade de produtos sustentáveis no momento da compra.

A pesquisa ainda mostrou que no Brasil a reciclagem é uma das práticas ambientais mais praticadas pelo consumidor consciente. $\mathrm{O}$ que mais motiva as pessoas a comparem produtos verdes é a busca pela preservação e conservação do meio ambiente para as gerações futuras ou valores pessoais e estilo de vida.

Estes dados mostram como as questões relacionadas ao meio ambiente e a sustentabilidade tem o seu espaço e também como o setor de cosméticos orgânicos e naturais vem crescendo em uma escala global. 


\section{Referencial Teórico}

Neste capítulo do estudo serão apresentados e discutidos aspectos conceituais e estudos relacionados ao tema em questão desenvolvidos por outros autores, que servirão como fundamento para a análise realizada sobre a influência da sustentabilidade na decisão de compra do consumidor no setor de cosméticos. Serão abordadas teorias relativas ao comportamento do consumidor, bem como estudos efetuados sobre responsabilidade social e sustentabilidade.

\subsection{Comportamento do consumidor}

De acordo com Churchill e Peter (2012), consumidores são indivíduos que adquirem bens e serviços para si próprios ou para outros, e não para revendêlos. Para criar valor para os clientes, os profissionais da área de marketing precisam compreender a lógica que permeia o comportamento do consumidor, buscando entender porque os consumidores compram um determinado produto ou serviço.

O comportamento do consumidor se refere ao estudo dos processos quando pessoas escolhem, obtém, utilizam ou descartam produtos ou serviços, com o objetivo de satisfazer e realizar suas respectivas necessidades. Os profissionais de marketing assimilaram que o comportamento do consumidor é um processo contínuo, que envolve questões de pré-compra, questões de compra e questões de pós-compra. (SOLOMON, 2016).

$\mathrm{Na}$ visão de alguns autores, as questões de pré-compra envolvem a constatação e o reconhecimento do consumidor de que ele precisa de um produto e a procura de fontes de informações a respeito das opções disponíveis no mercado. As questões de compra dizem respeito à aquisição do produto de fato e se a experiência de aquisição deste produto foi exaustiva ou agradável. Por último, as questões de pós-compra fazem referência à satisfação do consumidor e se o produto desempenha a sua função corretamente. (HAWKINS, MOTHERSBAUGH e BEST, 2007; SOLOMON, 2016). 
Segundo Hawkins, Mothersbaugh e Best (2007) o comportamento do consumidor abrange o estudo de indivíduos, grupos ou organizações e o processo que eles usam para selecionar, adquirir e utilizar produtos e serviços para satisfazer as suas necessidades. O comportamento do consumidor envolve uma investigação a respeito das influências indiretas sobre as decisões de compra de consumo, assim como as consequências de longo prazo que vão além da relação comprador e o vendedor.

Muitas decisões do consumidor centralizam-se nos sentimentos, emoções e sensações relacionadas à aquisição ou uso da marca ou ainda à circunstância em que o produto é adquirido ou utilizado. Os consumidores podem ter dois tipos de problemas: um problema ativo (o consumidor está ciente do problema) ou um problema inativo (o consumidor não está ciente do problema). Cada tipo de problema requer uma estratégia de marketing distinta. Nos problemas inativos é necessário que os profissionais façam os consumidores acreditarem que eles possuem um problema, já nos problemas ativos não é necessário. (HAWKINS, MOTHERSBAUGH e BEST, 2007).

Segundo Cerqueira (2013), a compra de cosméticos é baseada principalmente nos seus benefícios e na satisfação que o cosmético traz ao consumidor, que busca por uma melhor aparência diante da sociedade, bemestar e autoestima. Estilo de vida também é um importante fator que distingue a decisão e o comportamento de compra.

\subsubsection{Influência}

Para alguns autores, o comportamento do consumidor é influenciado principalmente por fatores culturais, sociais e pessoais, dentre eles os fatores culturais são os que desempenham maior influência. Os profissionais de marketing devem atentar sobretudo para os valores culturais de cada país, buscando compreender qual será a melhor maneira de levar seus produtos aos consumidores. Uma das maneiras pelas quais uma comunidade influencia o comportamento das pessoas é através da sua cultura, que abrange os valores e comportamentos que são partilhados por toda uma comunidade. A definição de cultura salienta os valores básicos, aqueles que são disseminados e propagados pelos indivíduos. (KOTLER e KELLER, 2012; CHURCHILL e PETER, 2012)

Segundo Solomon (2016), algumas questões podem afetar a decisão de compra do consumidor em uma situação de compra. As escolhas dos consumidores podem ser afetadas por fatores pessoais (humor ou pressão do 
tempo) pelo ambiente social e físico e por fatores temporais (tempo de espera). Alguns valores como conveniência no momento de compra, atendimento rápido ou facilidade de uso do produto em questão, também podem vir a influenciar o consumidor.

De acordo com Hawkins, Mothersbaugh e Best (2007), os consumidores reagem às influências de marketing e à circunstância ao mesmo tempo. A influência situacional envolve todos os fatores intrínsecos a um determinado momento, que não se desdobram de um entendimento dos atributos estáveis e inalteráveis do consumidor e que têm uma implicação sobre o comportamento. Segundo os autores, o comportamento do consumidor acontece dentro de quatro tipos de situações: a situação de comunicação, a situação de compra, a situação de uso e a situação de descarte.

A circunstância em que o consumidor recebe informações tem influência sobre o seu comportamento. O fato de o indivíduo estar sozinho ou não, com boa disposição ou não, influencia o grau e a intensidade em que esse indivíduo observa e ouve uma comunicação de marketing. Os profissionais de marketing trabalham para colocar as propagandas em um âmbito adequado de mídia para aumentar sua efetividade. A circunstância e o momento em que uma compra é realizada também pode influenciar o comportamento de um consumidor. A falta de tempo, o número de marcas consideradas e o preço que o consumidor está propenso a pagar ou ainda estar ou não com um "clima de compra" influenciam o comportamento do consumidor. O dever dos profissionais de marketing é compreender de que forma as situações de compra influenciam os consumidores, para criar estratégias adequadas. (HAWKINS, MOTHERSBAUGH e BEST, 2007).

Os profissionais de marketing também devem compreender as situações de uso para as quais seus produtos são apropriados, desta forma, é possível comunicar aos consumidores de que maneira seus produtos podem criar satisfação em cada situação de uso. As decisões e os julgamentos feitos pelos consumidores em relação à situação de descarte podem gerar problemas sociais, assim como oportunidades para os profissionais de marketing. Alguns consumidores levam em conta a facilidade de descarte no momento de adquirir um item e estes indivíduos podem comprar apenas produtos facilmente recicláveis, desta forma os profissionais devem compreender de que forma as influências situacionais afetam as decisões de descarte, para que possam criar produtos mais éticos. (HAWKINS, MOTHERSBAUGH e BEST, 2007). 
Segundo Silva e Bertrand (2009) os consumidores são influenciados principalmente pela qualidade do produto, pelo preço, pela conveniência e por último pela reputação socialmente responsável das empresas. De acordo com os autores, a falta de importância dada à reputação socialmente responsável das empresas repercute no comportamento negativo dos consumidores em relação à compra socialmente responsável. Os resultados da pesquisa feita pelos autores mostraram que os consumidores têm uma atitude positiva em relação à aquisição de produtos socialmente responsáveis, porém na prática os consumidores não se comportam desta forma.

Ainda segundo os autores, para os consumidores faltam informações sobre produtos socialmente responsáveis por parte das empresas, o que pode ser um fator que influencia negativamente os consumidores na hora de comprar um produto sustentável.

De acordo com Arcos, Matos, Dutra e Lima (2015) a qualidade e o preço são os fatores mais decisivos no momento de compra. Na pesquisa feita pelos autores (com consumidores de Fortaleza, capital do estado do Ceará) através de um questionário que teve como objetivo avaliar a sensibilidade do consumidor em relação as práticas sustentáveis das empresas de detergentes para roupas e seus produtos verdes, eles chegaram a conclusão de que o conceito de produto sustentável é importante para os consumidores, contudo, ainda faltam informações a respeito dos produtos ambientalmente corretos, acabando por não influenciar na tomada de decisão.

\subsubsection{Envolvimento do consumidor}

Na visão de Solomon (2016) envolvimento é a percepção do consumidor do grau de relevância de um determinado produto, com base em seus valores e interesses. Fatores distintos podem criar o envolvimento do consumidor (fatores pessoais, fatores do objeto ou do estímulo ou fatores situacionais). Contudo, nem todos são motivados na mesma intensidade e apresentam igual interesse.

Solomon (2016) enumera três tipos de envolvimento, sendo eles: envolvimento com o produto, envolvimento com a mensagem e envolvimento situacional. $\mathrm{O}$ envolvimento com o produto refere-se ao interesse e afeição do consumidor por um determinado produto. As decisões referentes aos produtos costumam ser muito envolventes se o indivíduo acreditar que existe um risco percebido no momento de compra. Ou seja, o consumidor pode presumir que haverá consequências ruins em detrimento de uma escolha errada. O risco 
percebido também é maior quanto mais caro ou complexo for o produto. 0 envolvimento com a mensagem refere-se às formas pelas quais a mídia consegue influenciar os consumidores e chamar sua atenção. A mídia impressa por exemplo, pode ser considerada como um meio de alto envolvimento, já a televisão é considerada como de baixo envolvimento. Por último, o envolvimento situacional envolve as lojas físicas, sites ou qualquer localidade em que os indivíduos adquirem produtos.

Houston e Rothschild (1977) definiram dois tipos de envolvimento: o envolvimento situacional e o envolvimento duradouro. $O$ conceito de envolvimento situacional implica que as situações diferem no que se refere a sua tendência de causar interesse e/ou comportamentos relativos à situação. O nível de envolvimento situacional deriva dos aspectos da situação que são externos ao indivíduo.

Os autores propõem duas categorias de estímulo que podem levar a menores ou maiores níveis de interesse e envolvimento. A primeira categoria faz referência aos estímulos relacionados ao objeto ou à questão pela qual o comportamento é direcionado. Segundo os autores (HOUSTON e ROTHSCHILD, 1977) o preço é a característica e variável mais aparente do produto que determina diretamente o envolvimento situacional.

A frequência de compra é outra variável específica relacionada ao objeto. Produtos comprados com maior frequência envolvem menor complexidade na sua procura e maior facilidade na tomada de decisão do consumidor.

A segunda categoria de estímulo faz referência àqueles estímulos que proveem das ocasiões sociais e psicológicas da aquisição ou consumo de um produto. O estímulo social mais fundamental no que se refere ao consumo do produto é a expectativa de ter alguém presente ou não durante o consumo.

Houston e Rothschild (1977), também definiram o envolvimento duradouro. Este envolvimento faz referência essencialmente ao relacionamento préexistente entre um indivíduo e um produto. A força e intensidade deste relacionamento são refletidas pelas experiências anteriores do indivíduo e as suas necessidades genéricas da situação e a relação entre os valores de um indivíduo com um produto.

A tendência é de que o envolvimento do consumidor seja baixo em uma situação nova e que exista um alto envolvimento duradouro quando um produto faz referência e é tocante aos valores mais importantes e significativos de um indivíduo. 
De acordo com artigo de Isaac (2016) a assimilação do valor dos cosméticos sustentáveis, sua relevância e seus benefícios percebidos pelos consumidores está limitada ainda às vantagens para a saúde e bem-estar (uso de componentes naturais) os consumidores acreditam que os cosméticos sustentáveis são mais saudáveis para a pele e para a saúde. A pesquisa foi feita com consumidores (em sua maioria jovens do sexo feminino) do município de São João da Boa Vista, do estado de São Paulo e teve como objetivo analisar o processo de tomada de decisão em relação a compra de cosméticos orgânicos e naturais e identificar os fatores que influenciam o consumidor no momento de compra.

O autor chegou à conclusão de que essa convicção é reforçada quando os consumidores adotam uma alimentação mais saudável e natural e que isso impulsiona o consumo de cosméticos orgânicos e naturais. Contudo, estes consumidores ainda não agregam muito valor e não fazem uma ligação entre a produção cosmética e o conceito sustentável, como a adoção de práticas de sustentabilidade, o fim dos testes em animais ou o uso de embalagens biodegradáveis ou recicláveis. A aquisição de cosméticos ainda se baseia nos benefícios apresentados pelo cosmético e no seu valor final. O preço elevado dos produtos naturais ainda é uma barreira no processo de compra.

Segundo Isaac (2016), a demanda por cosméticos sustentáveis é menor do que a demanda por cosméticos convencionais, o que pode ser explicado pela falta de conhecimento dos benefícios e vantagens dos cosméticos sustentáveis pelos consumidores.

\subsubsection{Motivação}

De acordo com Hawkins, Mothersbaugh e Best (2007) a motivação é a causa do comportamento. Um motivo surge através de uma força interna do consumidor que o estimula e se traduz em uma resposta comportamental, fazendo-o agir de uma certa maneira. Tanto as necessidades quanto os motivos induzem o que os consumidores entendem e compreendem como pertinente e também instigam suas emoções e sentimentos.

Na visão de Kotler e Keller (2012), uma necessidade se torna um motivo quando atinge um certo grau de intensidade capaz de impulsionar um individuo a realizar uma ação. A motivação engloba tanto um direcionamento, quanto uma intensidade. Para entender o comportamento do consumidor é preciso compreender os fatores psicológicos que levam a tomadas de decisões. A 
motivação está entre esses fatores. Sigmund Freud chegou à conclusão de que as forças psicológicas que constituem o comportamento das pessoas são em sua essência inconscientes e que não se pode entender inteiramente as motivações pessoais de cada indivíduo.

Segundo Churchill e Peter (2012) e Solomon (2016) a motivação abrange os processos que têm a capacidade de fazer os indivíduos se comportarem de uma certa maneira. A motivação acontece quando uma necessidade é provocada. Os autores enumeram dois tipos de necessidades: utilitárias e hedônicas. As necessidades utilitárias se baseiam nas funções básicas, primárias e nos benefícios percebidos, o consumidor inclina-se a ter um comportamento mais racional. As necessidades hedônicas, por outro lado, estão ligadas ao desejo e ao prazer, o consumidor toma decisões com base em seus sentimentos.

Segundo Olander e Thogersen (1995, p. 345 apud JOSHI e RAHMAN, 2015, p. 130) o modelo MAO (Motivation - Ability - Opportunity) foi introduzido para entender o comportamento do consumidor. Segundo este modelo, a habilidade e a oportunidade são pré-requisitos indispensáveis para o comportamento do consumidor verde. A habilidade diz respeito aos hábitos dos indivíduos assim como ao conhecimento da tarefa. A oportunidade se refere às condições facilitadoras ou à "oportunidade" de realizar tal comportamento. De acordo com este modelo, as atitudes positivas dos consumidores os levarão a um comportamento desejado apenas se eles tiverem a habilidade ou a oportunidade de realizar o comportamento esperado. Segundo esta teoria, a compra de produtos verdes não acontecerá sem fácil disponibilidade destes produtos no mercado.

Segundo Joshi e Rahman (2015) as atitudes positivas dos consumidores em relação a produtos verdes nem sempre se traduzem na compra de fato. Existe uma discrepância entre as atitudes favoráveis dos consumidores e a prática da compra de fato.

De acordo com Vicente, Matsubara e Eiro (2012) os principais motivos para a não procura por empresas de cosméticos sustentáveis são: o fato dos consumidores não pensarem sobre o assunto, não conseguirem diferenciar um cosmético convencional de um sustentável e o fato de comprarem levando em conta a qualidade do produto. Em contrapartida, os principais motivos para a procura por empresas de cosméticos sustentáveis são: o meio ambiente, futuro do planeta e valores pessoais dos consumidores. 
Os principais fatores que motivam os consumidores a adquirirem produtos verdes são: a preocupação com o meio ambiente e os atributos funcionais e verdes dos produtos. A preocupação dos consumidores e seu senso de responsabilidade no que diz respeito ao meio ambiente, têm um impacto positivo na aquisição de produtos verdes. (VICENTE, MATSUBARA e EIRO, 2012).

Ainda segundo os autores, fatores como o hábito dos consumidores e comportamentos passados, falta de confiança dos consumidores em produtos verdes e seus atributos e ainda a falta de informação a respeito destes produtos podem ser barreiras e afetar negativamente a aquisição de produtos verdes.

\subsubsection{Tomada de decisão}

De acordo com Kotler e Keller (2012) e Solomon (2016) o processo de compra tem início quando o consumidor identifica um problema ou uma necessidade, que pode ser uma necessidade normal de um indivíduo (fome, sede) ou uma necessidade ocasionada por estímulos externos. Pode-se discernir a busca de informações entre dois níveis de interesse, um em que o indivíduo está mais suscetível a receber informações a respeito de um produto e o outro em que o indivíduo busca intensamente por informações. Normalmente, o consumidor obtém informações por fontes comerciais, contudo, as informações mais concretas são obtidas de fontes pessoais ou públicas.

$\mathrm{Na}$ avaliação de alternativas, terceira etapa do processo, o consumidor precisa analisar as informações e fazer um julgamento. O consumidor faz julgamentos baseado nos benefícios relacionados a escolha do produto e no seu conjunto de atributos, que correspondem e são capazes de satisfazer as suas necessidades. (KOTLER e KELLER, 2012; SOLOMON, 2016).

No estágio de decisão de compra, o consumidor pode passar por cinco subdecisões, sendo elas: decisão por marca, decisão por revendedor, decisão por quantidade, decisão por ocasião e decisão por forma de pagamento. Existem alguns fatores que podem intervir na decisão de compra do consumidor, como, a influência da atitude de outras pessoas em relação à intenção de compra do consumidor. O segundo fator está ligado aos fatores situacionais imprevistos e por últimos aos riscos percebidos pelo consumidor na intenção de compra. (KOTLER e KELLER, 2012; SOLOMON, 2016).

O último estágio é o comportamento pós-compra. Após a compra do produto, os profissionais de marketing devem ficar atentos a questões relacionadas à satisfação pós-compra do cliente (que oscila entre as suas 
expectativas e o desempenho do produto em questão) e também devem observar como os clientes descartam os produtos após a sua utilização. (KOTLER e KELLER, 2012; SOLOMON, 2016).

Solomon (2016) enumera três tipos de tomada de decisão: tomada de decisão cognitiva, tomada de decisão habitual e tomada de decisão afetiva. $\mathrm{Na}$ tomada de decisão cognitiva, o consumidor analisa cautelosamente todas as informações que ele possui sobre o produto, avaliando todos os prós e os contras para chegar a uma resolução.

$\mathrm{Na}$ tomada de decisão habitual, por ser uma compra rotineira, o consumidor escolhe uma alternativa sem muito esforço e sem muita dificuldade. Por último, na tomada de decisão afetiva, o consumidor se fundamenta nas suas emoções em relação à escolha de um determinado produto.

De acordo com Hawkins, Mothersbaugh e Best (2007) os consumidores fazem muitas decisões baseados no menor preço, contudo, o consumidor pode tomar uma decisão baseado em diversos outros fatores, como nas emoções relacionadas à compra de uma determinada marca. Geralmente, a tomada de decisão do consumidor é baseada em um único problema.

Segundo Isaac (2016) o principal fator que afeta a decisão de compra do consumidor é a convicção de que os cosméticos sustentáveis são de fato mais benéficos para a pele e para a saúde. $O$ fácil acesso e conhecimento da marca também são fatores que influenciam na decisão de compra. Por outro lado, a composição e os ingredientes dos produtos e a sua disponibilidade no mercado são fatores que afetam pouco a decisão de compra. De acordo com o autor, a disponibilidade de cosméticos sustentáveis pode ou não influenciar o processo de tomada de decisão do consumidor.

\subsection{Responsabilidade social}

Segundo Tachizawa (2015, p.55) a responsabilidade social pode ser sintetizada como "o alcance de objetivos do desenvolvimento econômico-social". Desta forma, uma empresa é eficiente quando possui uma conduta socialmente responsável. De acordo com Simões, Ferreira, Afonso e Bartholo (2008) a responsabilidade social empreende uma expansão da atuação e operação de uma organização, indo de uma atuação interna para uma atuação externa. $\mathrm{Na}$ atuação interna o foco é nos empregados e na gestão de qualidade de vida no trabalho. Já na atuação externa, o foco é na comunidade e no desenvolvimento social local. 
De acordo com Tachizawa (2015) um dos desafios que a atualidade deve confrontar é conseguir com que as organizações e empresas preservem e aperfeiçoem a qualidade do ambiente em que estão inseridas. A atual conjuntura configura-se por uma severa atitude e comportamento dos clientes, direcionada a perspectiva de se relacionar com organizações que sejam éticas e tenham princípios morais.

A tendência de conservação e precaução ambiental e ecológica por parte das empresas deve seguir inalterável e permanentemente. Os resultados econômicos das organizações derivam de decisões que considerem que: não existe um enfrentamento entre as questões ligadas à lucratividade e à questão ambiental, ao fato de que o movimento ambientalista vem crescendo cada vez mais, em uma proporção global, a preocupação de consumidores e sociedade com a proteção do meio ambiente e por último a dependência entre o comportamento do consumidor, que preza por produtos e empresas ecologicamente corretas e o faturamento das empresas. (TACHIZAWA, 2015)

Ainda segundo o autor, a responsabilidade social transformou-se em um significativo instrumento gerencial, principalmente em relação à competitividade no mercado e também à sobrevivência. Os profissionais de administração devem compreender que precisa existir um equilíbrio e um balanço entre crescimento econômico e conservação ambiental. A proteção do meio ambiente passou a ser uma função da administração das organizações.

De acordo com Simões, Ferreira, Afonso e Bartholo (2008) para a responsabilidade social a atuação é um procedimento ininterrupto, onde objetivos e metas precisam ser revistos continuadamente, procurando sempre se alcançar uma melhoria constante, no que diz respeito à ética, à transparência, à cooperação e sobretudo à sustentabilidade.

Segundo os autores, ao adotarem a responsabilidade social e a sustentabilidade em sua gestão estratégica, as empresas devem se esforçar e se dedicar para adotar ideias que lhe dão a possibilidade e as condições necessárias para exercer a responsabilidade e sustentabilidade (qualidade de vida, valorização do meio ambiente nas empresas).

No momento em que uma organização incorpora em sua gestão as apreensões relacionadas ao impacto que suas atividades podem vir a causar no meio ambiente e desenvolve um espaço propício que estimule e proporcione relações transparentes com todos, se comprometendo com questões voltadas à sustentabilidade, ela está na direção da responsabilidade social. (SIMÕES, FERREIRA, AFONSO e BARTHOLO, 2008). 
Segundo Oliveira e Guimarães (2017) o conceito de responsabilidade social engloba as relações com as diversas partes com que as organizações estabelecem uma relação: acionistas, funcionários, consumidores, fornecedores, meio ambiente e comunidade. A responsabilidade social das empresas se refere ao engajamento com as necessidades da sociedade, objetivando a melhoria das condições e qualidade de vida.

John Elkington, fundador e um dos diretores da consultoria SustainAbility (focada na melhoria econômica, social e sustentabilidade ambiental) criou o termo triple bottom line em 1994. De acordo com este termo, as organizações devem ter como interesse não somente as questões voltadas para o aspecto financeiro e econômico, as questões ambientais e sociais também devem ser igualmente relevantes. (SIMÕES, FERREIRA, AFONSO e BARTHOLO, 2008).

É importante que as organizações considerem os contextos culturais em que estão inseridas e os impactos que suas ações podem vir a causar neste contexto. É primordial ponderar tudo em uma complexa malha de relações, que abrange fornecedores, consumidores e parceiros. Isto acarreta na inserção das dimensões ambiental e social na gestão estratégica das organizações, além da questão econômica. (SIMÕES, FERREIRA, AFONSO e BARTHOLO, 2008).

\subsection{Sustentabilidade}

De acordo com Nascimento (2012) o estilo de vida atual é bem diferente se comparado com o estilo de vida das gerações anteriores. Ao longo do tempo, houve uma redução significativa do espaço (devido ao aumento exorbitante da população) as reservas de recursos naturais renováveis diminuíram consideravelmente e os consumos de energia e de lixo aumentaram. Ou seja, o desenvolvimento tornou-se insustentável.

No fim da década de 80, foi quando a preocupação com o meio ambiente e com a sua proteção se tornou global. Já na década de 90 pode-se perceber que as pessoas já estão mais preocupadas em manter o equilíbrio ambiental. No final do século $X X$ e início do século $X X I$ nota-se uma grande mudança, onde a questão ambiental extrapola os limites de ações feitas isoladamente, para se tornar um alvoroço de toda uma sociedade. A sustentabilidade deixou de ser apenas uma função de proteção para se tornar também uma função ligada à administração das organizações. (NASCIMENTO, 2012).

Ainda segundo o autor, a sustentabilidade deixou de ser apenas uma resolução voltada a episódios socioambientais negativos, para ser então uma 
função integrada à gestão estratégica da administração das empresas, que passa a influenciar as tomadas de decisões e os negócios dentro das organizações. A sustentabilidade pode ser tida como uma ética. Não existirá sustentabilidade ambiental sem que haja também a sustentabilidade social.

De acordo com Silva (2017) sustentabilidade pode ser definida como a competência de satisfazer as necessidades e urgências do presente sem afetar e prejudicar as futuras gerações. As organizações vêm cada vez mais praticando ações de sustentabilidade, garantindo dessa forma a conservação dos recursos naturais para as futuras gerações. As organizações determinam em seus objetivos a sustentabilidade associada à responsabilidade social, buscando satisfazer as necessidades tanto da comunidade como do meio ambiente.

Segundo Nascimento (2012) o desenvolvimento sustentável tem o objetivo de incentivar e estimular a harmonia entre os homens e o meio ambiente. $O$ desenvolvimento sustentável não se restringe apenas ao impacto da atividade econômica na natureza, mas também às consequências da relação atividade econômica para com a natureza no bem-estar da comunidade. 0 desenvolvimento sustentável deve ser justo com a sociedade, responsável no que diz respeito ao meio ambiente e economicamente viável.

O autor também menciona a necessidade de integrar os aspectos ambientais nas fases de desenvolvimento de produtos, procurando dessa forma reduzir os impactos negativos à natureza, além de oferecer aos consumidores produtos sustentáveis e ambientalmente corretos. Em um mundo cada vez mais globalizado, pode ser difícil pensar em um desenvolvimento sustentável, porém, é este desenvolvimento que é capaz de proporcionar a geração de trabalho e renda de uma forma mais sustentável, levando em conta as questões econômicas, sociais e ambientais.

De acordo com Simões, Ferreira, Afonso e Bartholo (2008) a definição de sustentabilidade tornou-se mais ampla, abrangendo o crescimento econômico, a proteção ambiental, a igualdade social, a sustentação da identidade cultural e a sustentabilidade associada ao desenvolvimento. A sustentabilidade envolve a conciliação dessas questões, o que não é um encargo fácil para as empresas.

Integrar a sustentabilidade aos negócios das empresas envolve a inclusão de tecnologias que viabilizem uma menor utilização de recursos naturais, mas também a inserção nas organizações do que se entende por justiça ambiental, ética empresarial e igualdade social. Para que as organizações consigam adotar a sustentabilidade na sua gestão estratégica é preciso que primeiramente ela conheça os seus recursos para depois estabelecer ações e práticas sustentáveis 
e socialmente responsáveis. (SIMÕES, FERREIRA, AFONSO e BARTHOLO, 2008).

Ainda segundo os autores, para uma empresa ser sustentável do ponto de vista ambiental, ela deve gerar formas de avaliação que viabilizem melhores tomadas de decisão e um maior investimento no que diz respeito à proteção ambiental. No que diz respeito à dimensão social, as empresas devem assimilar que elas se sustentam das forças das pessoas e das comunidades. Algumas questões são ponderadas pelas organizações, como por exemplo: relações de confiança e honestidade com a comunidade, geração de empregos, estabilidade da população, criação de oportunidades e atenção aos direitos humanos. Para uma empresa ser sustentável do ponto de vista econômico, ela deve incluir o capital humano e o capital intelectual (medida do conhecimento, experiência e do potencial das pessoas) na sua contabilidade e nos documentos.

Segundo Silva e Fernandes (2016) é notória a preocupação com o meio ambiente pelas empresas que integraram a sua pesquisa (Natura, O Boticário, Procter\&Gamble e Avon). Concluiu-se que estas empresas têm as questões ambientais e sociais incorporadas na sua gestão estratégica, reduzindo os impactos ao meio ambiente e a melhora da comunidade local. As empresas gradativamente vêm compreendendo a inevitabilidade da preservação ambiental.

Fonseca, Rocha e Spers (2014) concluíram que existe a probabilidade de o público pesquisado não conhecer as ações referentes ao meio ambiente, sociedade e comunidade local, executadas pela Natura e O Boticário. Ambas as empresas do setor cosmético enfatizam a consciência socioambiental, o valor das relações com os públicos de interesse e o reconhecimento de seus impactos no meio ambiente.

De acordo com Vicente, Matsubara e Eiro (2012) apesar da sustentabilidade ser um assunto muito propagado na atualidade e as empresas do setor de cosméticos realizarem ações voltadas para este tema, ele ainda não é critério e medida para o consumidor na hora da decisão de compra. Esta pesquisa foi feita apenas com respondentes do sexo feminino, com idade média de 32 anos e residentes da região metropolitana de São Paulo e teve como objetivo entender se as ações de sustentabilidade promovidas por empresas do setor de cosméticos interferem no comportamento do consumidor. Segundo o artigo, a indústria cosmética deve se empenhar em divulgar mais os atributos sustentáveis de seus produtos. 


\section{Metodologia}

Neste capítulo, o objetivo é esclarecer sobre as decisões de como a pesquisa foi conduzida. Este capítulo informa questões sobre a coleta de dados, seleção da amostra que foi estudada, procedimentos e instrumentos de coletas de dados que foram utilizados, as formas de tratamento e por último as limitações do método aplicado no estudo.

\subsection{Método de pesquisa utilizado}

Segundo Zikmund e Babin (2012, p. 112) "a pesquisa quantitativa pode ser definida como uma pesquisa de marketing que aborda os objetivos da pesquisa por meio de avaliação empírica que envolvem medição e análise numérica."

De acordo com Creswell (2007) investigar as relações entre as variáveis da pesquisa é essencial para responder as questões e hipóteses da pesquisa. A análise estatística assegura medidas ou observações para testar uma teoria.

O método de pesquisa utilizado foi uma pesquisa de campo quantitativa, através desta metodologia foi possível fazer inferências sobre as características, atitudes, posicionamentos e comportamento do consumidor frente às questões da pesquisa.

\subsection{Fontes de informação selecionadas para coletas de dados no estudo}

A amostra de estudo é não probabilística, nesta amostragem a probabilidade de qualquer integrante em particular da população ser escolhido não é conhecida, a seleção da amostra é feita arbitrariamente (ZIKMUND e BABIN, 2012). A amostragem escolhida foi por conveniência, modo pelo qual a aquisição de pessoas é feita baseada na sua disponibilidade e conveniência (ZIKMUND e BABIN, 2012).

A amostra da pesquisa foi composta majoritariamente por mulheres. A coleta de dados foi feita do dia 26/04 até o dia 02/05. Ao todo foram respondidos 147 questionários, contudo, apenas 135 foram respondidos completamente. A 
pesquisa foi direcionada a consumidores de cosméticos (perfumes, cremes para pele/rosto, maquiagem) e a amostra foi de consumidores entre 15 e 50 anos ou mais, de ambos os sexos e todas as classes sociais.

O questionário foi composto por 27 questões, as quais abordaram questões relacionadas ao comportamento de consumo em relação aos cosméticos e questões abrangendo o consumo de cosméticos relacionado a sustentabilidade. O questionário completo pode ser visto no Anexo 1.

\subsection{Procedimentos e instrumentos de coleta de dados utilizados no estudo}

O instrumento utilizado na pesquisa para coleta de dados foi um questionário desenvolvido pela autora, com base na revisão de literatura e nos objetivos da pesquisa e conteve questões que abordavam: dados sociodemográficos dos consumidores, comportamento de consumo em relação a cosméticos e questões abordando a sustentabilidade relacionada a cosméticos.

Por último foi utilizada uma escala likert de 5 níveis (que vai de "concordo totalmente" a "discordo totalmente") onde os respondentes apontam suas atitudes e posicionamentos de acordo com o seu grau de concordância em relação as afirmações feitas (ZIKMUND e BABIN, 2012).

Ao longo do questionário, também foram avaliadas algumas questões relacionadas às preocupações dos consumidores no momento da compra de cosméticos sustentáveis e questões que averiguam o comprometimento e envolvimento do consumidor com questões relacionadas a sustentabilidade.

A ferramenta utilizada para a coleta de dados foi um questionário online disponibilizado via Google Drive. O link da pesquisa foi divulgado pelas redes sociais. O questionário pode ser dividido em tópicos de acordo com a Tabela 1.

\begin{tabular}{|c|c|}
\hline Variável & Itens \\
\hline $\begin{array}{c}\text { Segmentação demográfica } \\
\text { Comportamento de consumo em } \\
\text { relação aos cosméticos }\end{array}$ & 5 questões \\
\hline Sustentabilidade & 6 questões \\
\hline $\begin{array}{c}\text { Motivos para compra e não compra de } \\
\text { cosméticos sustentáveis }\end{array}$ & 2 questões \\
\hline Preservação do meio ambiente & 8 questões \\
\hline Responsabilidade social & 2 questões \\
\hline
\end{tabular}

Tabela 1 - Resumo das variáveis da pesquisa 


\subsection{Formas de tratamento e análise dos dados coletados para o estudo}

A pesquisa teve como objetivo identificar a influência da sustentabilidade na tomada de decisão do consumidor em relação a compra de cosméticos. 0 método de pesquisa utilizado foi uma pesquisa descritiva, que possibilitou a análise e ordenação dos dados coletados, procurando dessa forma descobrir a frequência com que os fatos ocorrem, suas características, causas e relações com outros fatos.

Os dados coletados foram analisados de forma quantitativa com o auxílio do software Excel e de gráficos gerados pelo próprio Google Drive, onde mediuse o percentual, possibilitando a apresentação dos resultados da pesquisa.

\subsection{Limitações do estudo}

Uma das limitações do estudo é a possibilidade de os respondentes da amostra responderem ao questionário de maneira descuidada ou desleixada, indicando respostas que não condizem com as suas opiniões de fato.

Outra limitação encontra-se na população da amostra em que a maior parte se limita por mulheres e por residentes do Rio de Janeiro, além disso, o questionário foi disponibilizado somente via redes sociais o que limitou os respondentes a serem jovens estudantes na faixa etária de 21 a 30 anos com renda familiar de 1 a 3 salários mínimos.

O método utilizado no presente estudo trouxe algumas limitações para a pesquisa. De acordo com Prodanov e Freitas (2013, p. 38) "o papel do método estatístico é, essencialmente, possibilitar uma descrição quantitativa da sociedade, considerada como um todo organizado."

Diante disto, as respostas e explicações alcançadas através deste método não devem ser tidas como absolutamente verdadeiras, mas como uma boa chance de serem verdadeiras. De acordo com Oliveira, Melo, Prado e Bruggemann (2013) fenômenos complexos não podem ser compreendidos por questionários padrão e averiguados apenas com o rigor estatístico e matemático. Segundo Souza (1989) o método quantitativo generaliza e torna mais simples as complexidades em que os indivíduos vivem e estão inseridos, podendo levar a falhas por não considerar que a verdade tem várias vertentes. 


\section{Apresentação e análise dos resultados}

Este capítulo organizado em 4 itens irá demonstrar os resultados obtidos por meio da pesquisa que teve como objetivo entender melhor e averiguar a influência da sustentabilidade na decisão de compra dos consumidores por produtos cosméticos sustentáveis.

\subsection{Descrição dos resultados sociodemográficos}

A seguir serão apresentadas as principais características dos 135 respondentes desta pesquisa.

O perfil da amostra foi composto por ambos os sexos, porém, a presença de respondentes do sexo feminino foi muito maior, representando $80 \%$ da pesquisa. Em relação à faixa etária, os respondentes ficaram distribuídos como a seguir: na faixa de 15 a 20 anos (10,4\%), de 21 a 30 anos (57\%), de 31 a 40 anos $(11,1 \%)$ e acima de 50 anos (5,2\%). Portanto, a maior parte da amostra constitui-se por jovens adultos na faixa etária de 21 a 30 anos, que em sua maioria já possui renda.

Já por grau de instrução, os respondentes ficaram distribuídos em ensino fundamental completo $(0,7 \%)$, ensino fundamental incompleto $(0 \%)$, ensino médio completo $(6,7 \%)$, ensino médio incompleto $(0,7 \%)$, superior completo $(22,2 \%)$, superior incompleto $(51,1 \%)$ e pós-graduação $(18,5 \%)$. A maior parte da amostra possui um bom nível educacional.

Em relação à ocupação dos respondentes, a maior parte deles são estudantes que correspondem a $45,2 \%$ da amostra, em seguida vem os funcionários de empresas privadas $(24,4 \%)$ e funcionários de empresas públicas $(12,6 \%)$. No que se refere à renda familiar, pode-se observar que a maioria dos consumidores possui renda de 1 a 3 salários mínimos (49,6\%). 19,3\% possuem renda de 4 a 10 salários mínimos, seguido por $17 \%$ dos respondentes com renda de mais de 10 salários mínimos. 14,1\% possuem renda de até 1 salário mínimo. De acordo com o IBGE (Instituto Brasileiro de Geografia e Estatística) o valor do salário mínimo é de $R$ \$954. (G1, 2018).

A Tabela 2 sintetiza o perfil sociodemográfico dos respondentes da pesquisa realizada. 


\begin{tabular}{|c|c|c|c|c|c|}
\hline FAIXA ETÁRIA & FREQUÊNCIA & $\%$ & ESCOLARIDADE & FREQUÊNCIA & $\%$ \\
\hline De 15 a 20 anos & 14 & $10,40 \%$ & $\begin{array}{l}\text { Ensino fundamental } \\
\text { completo }\end{array}$ & 1 & $0,70 \%$ \\
\hline De 21 a 30 anos & 77 & $57,00 \%$ & $\begin{array}{l}\text { Ensino fundamental } \\
\text { incompleto }\end{array}$ & 0 & $0 \%$ \\
\hline De 31 a 40 anos & 22 & $16,30 \%$ & Ensino médio completo & 9 & $6,70 \%$ \\
\hline De 41 a 50 anos & 15 & $11,10 \%$ & Ensino médio incompleto & 1 & $0,70 \%$ \\
\hline Acima de 50 anos & 7 & $5,20 \%$ & Superior completo & 30 & $22,20 \%$ \\
\hline SEXO & FREQUÊNCIA & $\%$ & Superior incompleto & 69 & $51,10 \%$ \\
\hline Feminino & 108 & $80 \%$ & Pós-graduação & 25 & $18,50 \%$ \\
\hline Masculino & 27 & $20 \%$ & RENDA FAMILIAR & FREQUÊNCIA & $\%$ \\
\hline OCUPAÇÃO & FREQUÊNCIA & $\%$ & Até 1 salário mínimo & \begin{tabular}{|l|}
19 \\
\end{tabular} & $14,10 \%$ \\
\hline Estudante & 61 & $45,20 \%$ & De 1 a 3 salários mínimos & 67 & $49,60 \%$ \\
\hline $\begin{array}{c}\text { Funcionário de empresa } \\
\text { privada }\end{array}$ & 33 & $24,40 \%$ & $\begin{array}{c}\text { De } 4 \text { a } 10 \text { salários } \\
\text { mínimos }\end{array}$ & 26 & $19,30 \%$ \\
\hline $\begin{array}{c}\text { Funcionário de empresa } \\
\text { pública }\end{array}$ & 17 & $12,60 \%$ & $\begin{array}{c}\text { Mais de } 10 \text { salários } \\
\text { mínimos }\end{array}$ & 23 & $17,00 \%$ \\
\hline Outros & 24 & $17,80 \%$ & & & \\
\hline
\end{tabular}

Tabela 2 - Perfil sociodemográfico dos respondentes

A incidência de mulheres foi maior nesta pesquisa pelo fato de que as mulheres são as maiores consumidoras de cosméticos comparado aos homens. Os jovens foram a parcela mais representativa na pesquisa pela influência do uso das redes sociais da autora na aquisição de respostas.

\subsection{Comportamento do consumo de cosméticos}

Antes de entrar na questão da sustentabilidade relacionada à aquisição de cosméticos, buscou-se compreender melhor o comportamento e os hábitos de consumo dos respondentes em relação aos produtos cosméticos. A primeira pergunta feita aos respondentes foi: "Você compra cosméticos? (perfumes, cremes para pele/rosto, maquiagem)". $91,8 \%$ dos respondentes apontaram que sim e 8,2\% apontaram que não, estes não foram considerados na análise dos resultados desta pesquisa. O Gráfico 1 apresenta os resultados.

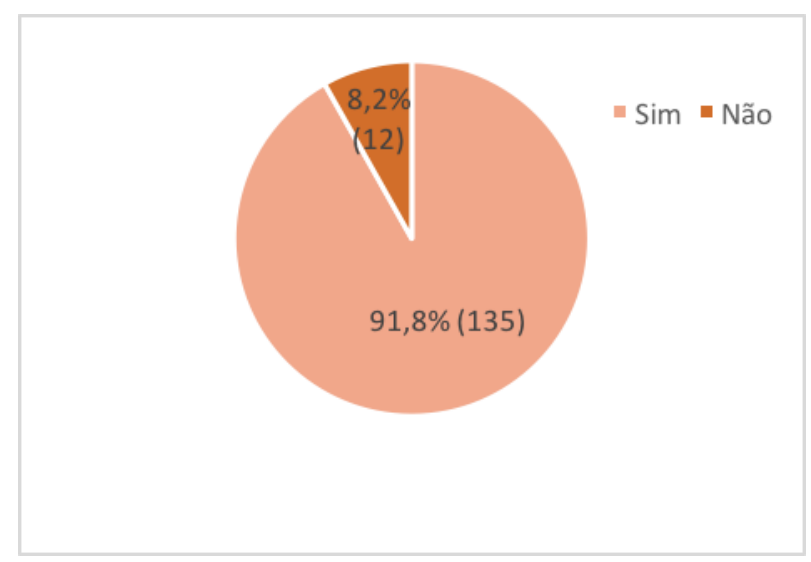

Gráfico 1 - Respostas à pergunta sobre compras 
Em seguida os respondentes foram questionados a respeito das principais formas de intermediação comercial que eles utilizam ao comprar produtos cosméticos. A farmácia foi o principal meio de intermediação assinalado pelos consumidores $(44,4 \%)$ seguida pela consultora $(39,3 \%)$ e pela perfumaria (36,3\%). O Gráfico 2 mostra as principais formas de intermediação buscadas pelos consumidores de cosméticos.

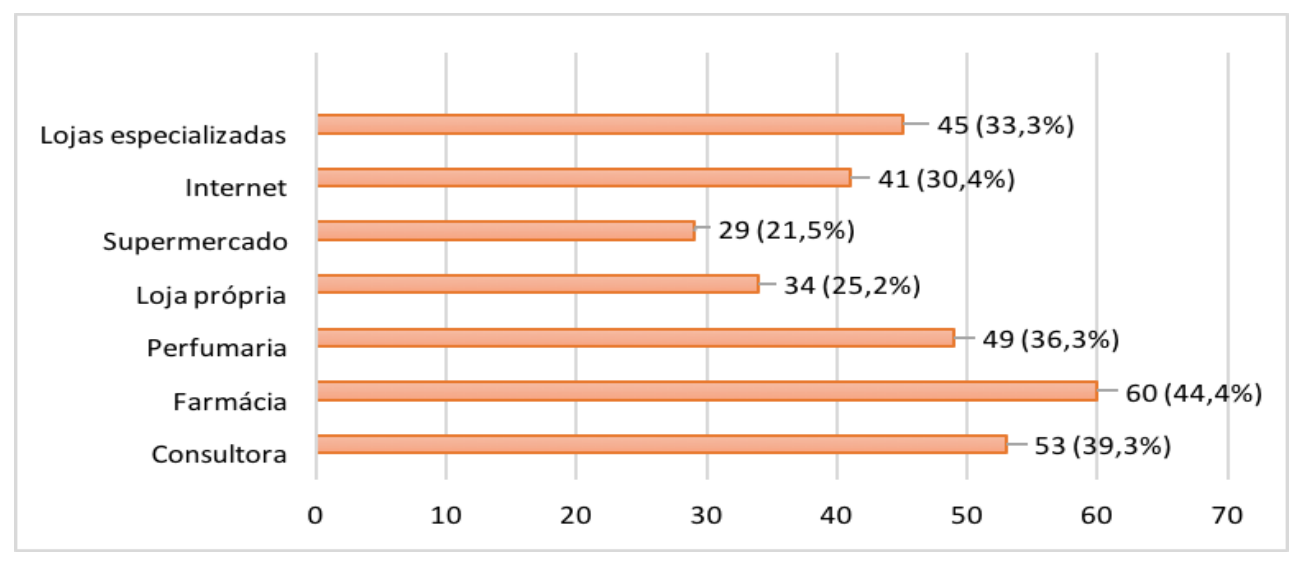

Gráfico 2 - Respostas à pergunta sobre intermediação comercial

Os respondentes também foram questionados sobre quais marcas de cosméticos eles costumam comprar. As marcas mais utilizadas são a Natura $(56,3 \%)$ seguida pela O Boticário (55,6\%) e pela Avon (43,7\%). Marcas como L'Oréal (33,3\%), MAC (24,4\%), Eudora (13,3\%), The Beauty Box (3\%), Quem disse Berenice $(16,3 \%)$ e The Body Shop (8,9\%) também foram apontadas na pesquisa. Houve um grande número de outras opções citadas na pesquisa, como Mary Kay, Hinode, Tracta, Ruby Rose, Nars e Urban Decay. O Gráfico 3 apresenta esse resultado.

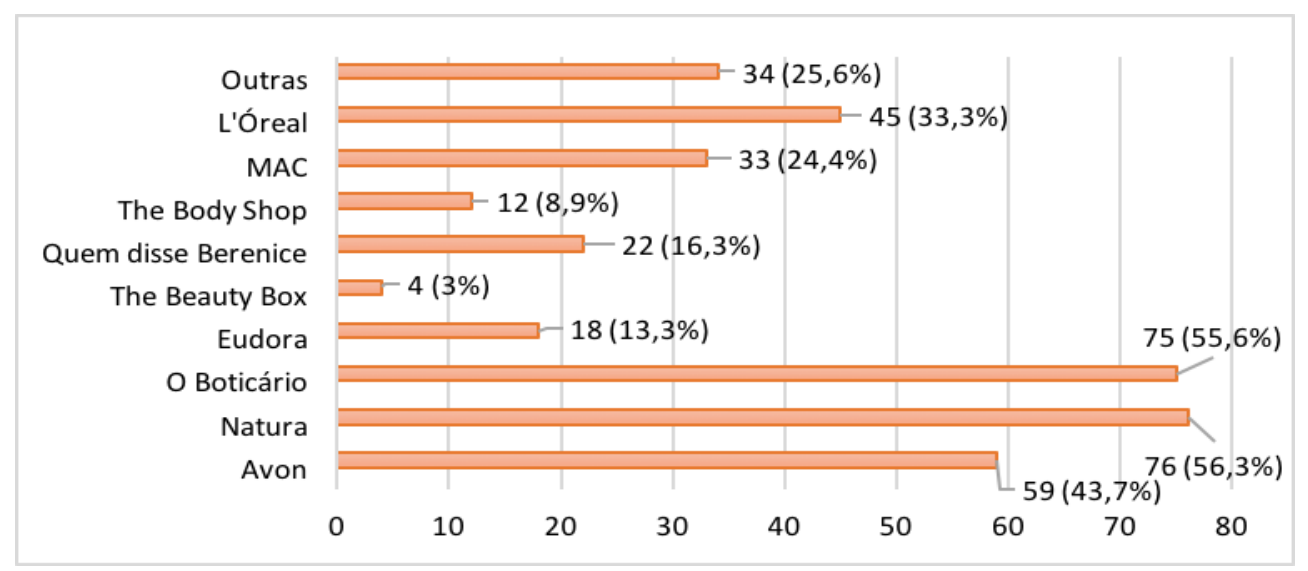

Gráfico 3 - Respostas à pergunta sobre marcas utilizadas 
Logo em seguida, foi perguntado aos consumidores quais são os critérios que eles utilizam para selecionar estas marcas. O principal critério é a qualidade do produto $(88,9 \%)$ seguido pelo preço $(54,1 \%)$ e indicação de terceiros $(34,8 \%)$. O critério de proteção ambiental/preservação do meio ambiente foi um dos menos apontados, correspondendo a apenas $26,7 \%$ dos respondentes. O Gráfico 4 apresenta esse resultado. Estes resultados reforçam os achados de Silva e Bertrand (2009) que apontam a qualidade do produto e o preço como maiores fatores de influência e por último a reputação socialmente responsável das empresas, o que repercute no comportamento negativo dos consumidores em relação a compra socialmente responsável.

De acordo com Hawkins, Mothersbaugh e Best (2007) o preço que o consumidor está propenso a pagar influencia o seu comportamento. O dever dos profissionais de marketing é compreender de que forma as situações de compra influenciam os consumidores, para criar estratégias adequadas. Segundo Kotler e Keller (2012) e Churchill e Peter (2012) os fatores sociais e pessoais desempenham influência sobre o comportamento do consumidor. De acordo com Solomon (2016) a conveniência no momento de compra também pode vir a influenciar o consumidor. Estas teorias reforçam os achados do presente estudo.

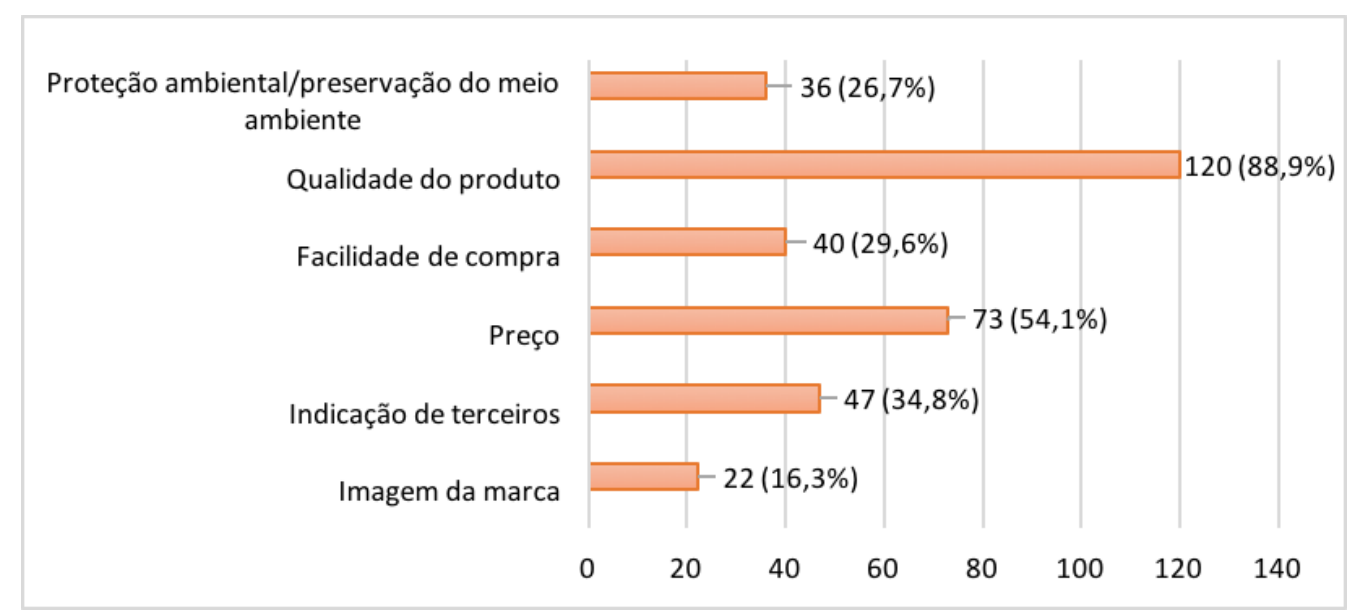

Gráfico 4 - Respostas à pergunta sobre critérios de seleção

Entrando na questão da sustentabilidade, os respondentes foram questionados sobre quais marcas eles associam ao tema. A Natura é a marca que os consumidores mais associam à sustentabilidade, correspondendo a $71,4 \%$ seguida pelo $O$ Boticário $(24,8 \%)$ e pela Avon (11,3\%). Poucos respondentes associaram marcas como Eudora, The Body Shop e L'Oréal à 
sustentabilidade, por outro lado, alguns não associaram nenhuma marca ao tema, representando $12 \%$ da amostra da pesquisa. Estes resultados reforçam os achados de Isaac (2016) onde os consumidores apontaram a Natura, O Boticário e a Avon como primeiras marcas de cosméticos que vem à sua mente, sendo marcas conhecidas pelo uso de ingredientes de origem vegetal na produção de seus cosméticos. Os resultados verificados no estudo de Silva e Bertrand (2009) também apontaram as marcas Natura e O Boticário como percebidas pelos consumidores de uma forma diferenciada, isso se deve em relação ao atributo de responsabilidade social associada a estas marcas. O Gráfico 5 mostra este resultado.

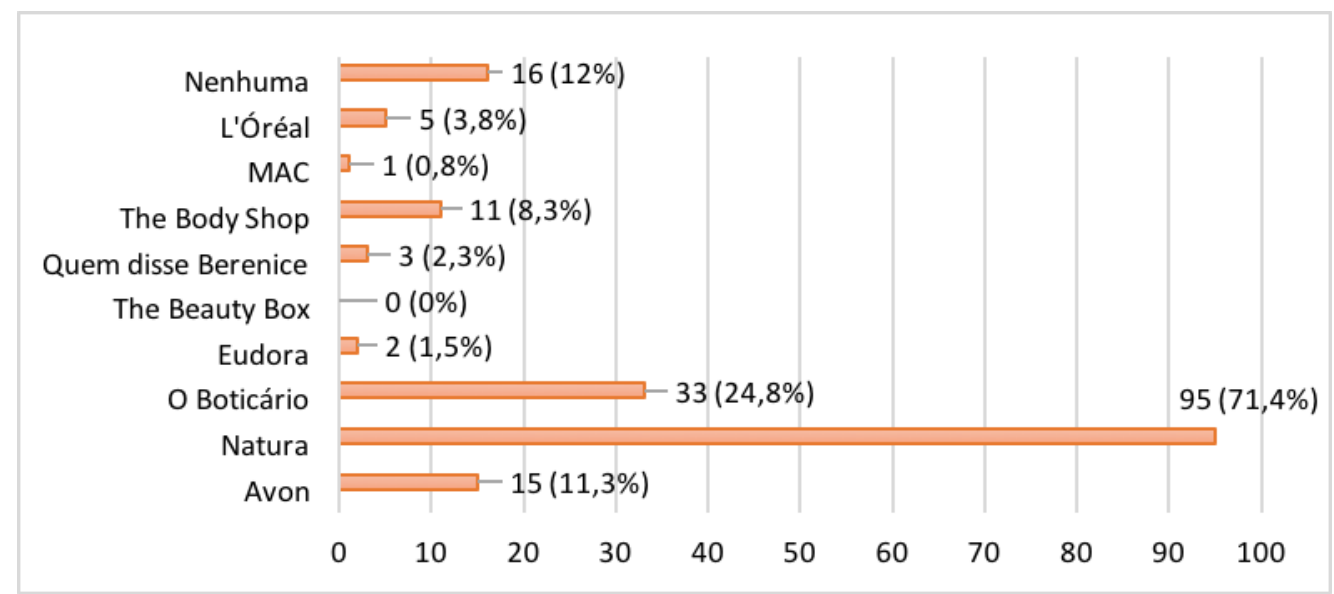

Gráfico 5 - Respostas à pergunta sobre marcas associadas a sustentabilidade

Algumas assertivas foram feitas aos consumidores em relação ao consumo de cosméticos. A primeira assertiva foi: "tenho o costume de verificar se o cosmético agride o meio ambiente". Como resultado $28,1 \%$ concordam totalmente e $26,7 \%$ concordam parcialmente. $23,7 \%$ não concordam, nem discordam. 8,1\% discordam parcialmente e 13,3\% discordam totalmente.

A segunda assertiva foi: "busco informações de novos produtos que não sejam nocivos ao meio ambiente". Como resultado apenas $31,9 \%$ concordam totalmente e $21,5 \%$ concordam parcialmente. 25,2\% não concordam, nem discordam. 8,1\% discordam parcialmente e 13,3\% discordam totalmente. A partir dessas duas assertivas, pode-se observar que a maioria dos consumidores tem o costume de verificar se o cosmético agride o meio ambiente e busca informações a respeito de produtos que não sejam nocivos ao meio ambiente. Estes resultados contradizem os achados de Isaac (2016) que aponta que os 
consumidores ainda não agregam muito valor e não fazem uma ligação entre a produção cosmética e o conceito sustentável.

De acordo com Solomon (2016) e Hawkins e Mothersbaugh (2007) o comportamento do consumidor envolve questões de pré-compra. As questões de pré-compra envolvem a constatação e o reconhecimento do consumidor de que ele precisa de um produto e a procura de fontes de informações a respeito das opções disponíveis no mercado. Antes da compra de cosméticos os consumidores buscam informações a respeito dos produtos e de novos produtos. A indicação de terceiros foi apontada pelos consumidores como um fator importante e fonte de informação no processo decisório de aquisição de um produto cosmético.

A terceira assertiva foi: "no momento de compra de um cosmético, tenho facilidade em distinguir um produto cosmético natural/orgânico dos demais". Como resultado $21,6 \%$ concordam totalmente e $23,9 \%$ concordam parcialmente. $17,9 \%$ não concordam, nem discordam. 11,9\% discordam parcialmente e 24,6\% discordam totalmente. Isto mostra que grande parte dos consumidores têm facilidade em distinguir um cosmético sustentável de um convencional. Este resultado contradiz os achados de Vicente, Matsubara e Eiro (2012) que apontam a dificuldade dos consumidores em distinguir um cosmético convencional de um sustentável, levando-os a não procurar marcas de cosméticos sustentáveis.

A última assertiva foi: "estou disposta a pagar um pouco mais por produtos cosméticos fabricados de forma sustentável". Como resultado $35,1 \%$ concordam totalmente e 32,1\% concordam parcialmente. 18,7\% não concordam, nem discordam. $8,2 \%$ discordam parcialmente e $6 \%$ discordam totalmente. Os resultados mostram que grande parte dos consumidores está disposto a pagar um pouco mais por produtos cosméticos sustentáveis. Este resultado contradiz os achados de Isaac (2016) e Houston e Rothschild (1977) que apontam que a aquisição de cosméticos ainda se baseia no seu valor final e que o preço é a característica e variável mais aparente do produto. $\mathrm{O}$ resumo destes resultados se encontra na Tabela 3.

Segundo Solomon (2016) existem três tipos de envolvimento, sendo um deles o envolvimento com o produto, que se refere ao interesse e afeição do consumidor por um determinado produto. As decisões referentes ao produto costumam ser muito envolventes se o indivíduo acreditar que existe um risco percebido no momento de compra. O risco percebido também é maior quanto mais caro ou complexo for o produto. Diante disto e dos resultados do estudo, 
pode-se perceber que o consumidor tem um certo interesse e afeição por produtos cosméticos fabricados de forma sustentável. Provavelmente a parcela de consumidores que não está disposta a pagar um pouco mais por este tipo de produto, percebe um risco elevado nessa aquisição.

\begin{tabular}{|c|c|c|c|c|c|c|c|c|c|c|}
\hline \multicolumn{11}{|c|}{ ESCALA DE LIKERT } \\
\hline Posição & Concordo to & talmente & Concordo pa & cialmente & Não concordo & em discordo & Discordo par & ialmente & Discordo to & almente \\
\hline Assertivas & FREQUÊNCIA & $\%$ & FREQUÊNCIA & $\%$ & FREQUÊNCIA & $\%$ & FREQUÊNCIA & $\%$ & FREQUÊNCIA & $\%$ \\
\hline $\begin{array}{c}\text { Tenho o costume de verificar } \\
\text { se o cosmético agride o meio } \\
\text { ambiente }\end{array}$ & 38 & $28,10 \%$ & 36 & $26,70 \%$ & 32 & $23,70 \%$ & 11 & $8,10 \%$ & 18 & $13,30 \%$ \\
\hline $\begin{array}{l}\text { Busco informaç̄oes de novos } \\
\text { produtos que não sejam } \\
\text { nocivos ao meio ambiente }\end{array}$ & 43 & $31,9 \% \%$ & 29 & $21,50 \%$ & 34 & $25,20 \%$ & 11 & $8,10 \%$ & 18 & $13,30 \%$ \\
\hline $\begin{array}{c}\text { No momento de compra tenho } \\
\text { facilidade em distinguir um } \\
\text { cosmético natural/orgânico } \\
\text { dos demais }\end{array}$ & 29 & $21,60 \%$ & 32 & $23,90 \%$ & 24 & $17,90 \%$ & 16 & $11,90 \%$ & 33 & $24,60 \%$ \\
\hline $\begin{array}{l}\text { Estou disposta a pagar um } \\
\text { pouco mais por produtos } \\
\text { cosméticos fabricados de } \\
\text { forma sustentável }\end{array}$ & 47 & $35,10 \%$ & 43 & $32,10 \%$ & 25 & $18,70 \%$ & 11 & $8,20 \%$ & 8 & $6 \%$ \\
\hline
\end{tabular}

Figura 1 - Respostas às assertivas sobre consumo de cosméticos

\subsection{Sustentabilidade associada ao consumo de cosméticos}

Entrando mais a fundo no tema da sustentabilidade, os consumidores foram questionados quanto a seu grau de interesse sobre o assunto. Os resultados da pesquisa mostraram que $63,7 \%$ da amostra possui muito interesse por assuntos relacionados à sustentabilidade e 34,1\% tem pouco interesse. Apenas $2,2 \%$ da amostra não possui nenhum interesse sobre 0 assunto. A Tabela 4 mostra este resultado.

\begin{tabular}{|c|c|c|}
\hline \multicolumn{3}{|c|}{$\begin{array}{l}\text { Qual é o seu interesse por assuntos } \\
\text { relacionados a sustentabilidade? }\end{array}$} \\
\hline RESPOSTAS & FREQUÊNCIA & $\%$ \\
\hline Muito interesse & 86 & $63,70 \%$ \\
\hline Pouco interesse & 46 & $34,10 \%$ \\
\hline Nenhum interesse & 3 & $2,20 \%$ \\
\hline
\end{tabular}

Tabela 3 - Respostas à pergunta sobre sustentabilidade 
Este resultado mostra que os assuntos relacionados a sustentabilidade tem uma grande relevância e espaço na atualidade e que os consumidores estão preocupados com as questões ambientais, contudo $34,1 \%$ dos respondentes têm pouco interesse sobre o assunto, ou seja, ainda é preciso que as pessoas criem uma maior consciência ambiental e se engajem mais com os assuntos relacionados a sustentabilidade. Este resultado reforça os achados de Vicente, Matsubara e Eiro (2012) que apontam que os consumidores são preocupados e têm senso de responsabilidade no que diz respeito ao meio ambiente, o que provavelmente os leva a ter um impacto e atitude positivos na aquisição de produtos sustentáveis.

Em seguida, os respondentes foram questionados se o fato da marca ter a opção de um cosmético sustentável influencia na sua decisão de compra. Os resultados mostraram que $68,1 \%$ dos respondentes são influenciados e $31,9 \%$ não são influenciados. Em um segundo momento, outra pergunta foi feita aos consumidores: "No momento de compra de cosméticos você procura por cosméticos sustentáveis? "Como resposta, 34,8\% da amostra disse que sim e $65,2 \%$ disse que não. A Tabela 5 e a Tabela 6 mostram estes resultados.

\begin{tabular}{|c|c|c|}
\hline \multicolumn{3}{|c|}{$\begin{array}{c}\text { Ter a opção de um cosmético sustentável } \\
\text { influencia na sua decisão de compra? }\end{array}$} \\
\hline RESPOSTAS & FREQUÊNCIA & $\%$ \\
\hline Sim & 92 & $68,10 \%$ \\
\hline Não & 43 & $31,90 \%$ \\
\hline
\end{tabular}

Tabela 4 - Respostas à pergunta sobre influência dos cosméticos sustentáveis

\begin{tabular}{|c|c|c|}
\hline \multicolumn{3}{|c|}{$\begin{array}{c}\text { No momento de compra de cosméticos você } \\
\text { procura por cosméticos sustentáveis? }\end{array}$} \\
\hline RESPOSTAS & FREQUÊNCIA & $\%$ \\
\hline Sim & 47 & $34,80 \%$ \\
\hline Não & 88 & $65,20 \%$ \\
\hline
\end{tabular}

Tabela 5 - Respostas à pergunta sobre compra de cosméticos sustentáveis

O resultado dessas duas perguntas mostra que os consumidores possuem uma atitude favorável a produtos sustentáveis, uma vez que a maior parte deles é influenciado por cosméticos sustentáveis, contudo, essa influência não se 
traduz na prática da compra, já que 65,2\% dos consumidores não procuram por cosméticos sustentáveis no momento da compra. Pode-se observar que os consumidores não consideram os cosméticos sustentáveis como primeira opção de compra, contudo, caso uma opção sustentável seja apresentada, o consumidor irá ponderar e considerar no momento da tomada de decisão. Esse resultado está alinhado com os estudos de Silva e Bertrand (2009) e Joshi e Rahman (2015) que apontam a existência de uma discrepância entre as atitudes favoráveis dos consumidores e a prática da compra de fato. Os consumidores têm uma atitude positiva em relação a aquisição de produtos socialmente responsáveis, porém na prática não se comportam desta forma.

O resultado do presente estudo contradiz os achados de Vicente, Matsubara e Eiro (2012) que apontam que a sustentabilidade ainda não é um fator influenciador e critério para o consumidor na hora da decisão de compra.

Através da pesquisa foi possível observar que 51,9\% dos consumidores não utilizam ou nunca utilizaram um cosmético orgânico ou natural, enquanto $48,1 \%$ dos respondentes já utilizaram um cosmético sustentável, conforme se observa na Tabela 7. Este resultado aponta uma diferença muito pequena e pouco significativa entre consumidores que já utilizaram ou utilizam cosméticos orgânicos ou naturais e os que não utilizam. O resultado reforça os achados de Isaac (2016) que aponta uma demanda menor por cosméticos sustentáveis do que a demanda por cosméticos convencionais. O autor relacionou este resultado ao desconhecimento dos benefícios dos cosméticos sustentáveis por parte do consumidor brasileiro.

De acordo com os achados de Isaac (2016) 39,22\% dos consumidores nunca utilizaram ou não utilizam cosméticos orgânicos ou naturais, ao passo que $35,32 \%$ já utilizaram ou utilizam.

Segundo Kotler e Keller (2012) e Solomon (2016) na avaliação de alternativas, o consumidor precisa analisar as informações e fazer um julgamento. O consumidor faz julgamento baseado nos benefícios relacionados a escolha do produto e no seu conjunto de atributos, que correspondem e são capazes de satisfazer as suas necessidades. De acordo com os achados do estudo os consumidores adquirem cosméticos sustentáveis baseado nos benefícios para a saúde/bem-estar e na qualidade dos produtos sustentáveis. 


\begin{tabular}{|c|c|c|}
\hline \multicolumn{3}{|c|}{$\begin{array}{c}\text { Você já utilizou ou utiliza um cosmético orgânico } \\
\text { ou natural? }\end{array}$} \\
\hline RESPOSTAS & FREQUÊNCIA & $\%$ \\
\hline Sim & 65 & $48,10 \%$ \\
\hline Não & 70 & $51,90 \%$ \\
\hline
\end{tabular}

Também foi possível observar ao que os respondentes associam as marcas de cosméticos sustentáveis. O resultado mostrou que $71,1 \%$ dos consumidores associam as marcas de cosméticos sustentáveis à sustentabilidade, $57,8 \%$ associam à responsabilidade social, 57\% associam à produtos orgânicos e naturais, 47,4\% associam ao fato destas marcas não fazerem testes em animais, 30,4\% associam aos projetos sociais feitos pelas marcas e 25,2\% associam à qualidade dos produtos sustentáveis. Pode-se observar que grande parte dos consumidores pensa em sustentabilidade e responsabilidade social ao analisar marcas de cosméticos sustentáveis. Estes resultados reforçam os achados de Arcos, Matos, Dutra e Lima (2015) que apontam a importância do conceito de produto sustentável para os consumidores. O Gráfico 6 mostra este resultado.

Segundo Tachizawa (2015) um dos desafios que a atualidade deve confrontar é conseguir com que as organizações e empresas preservem e aperfeiçoem a qualidade do ambiente em que estão inseridas. A atual conjuntura configura-se por uma severa atitude e comportamento dos clientes, direcionada à perspectiva de se relacionar com organizações que sejam éticas e tenham princípios morais. Esta teoria reforça os achados do estudo, já que as maiores associações feitas pelos consumidores às marcas de cosméticos sustentáveis são relacionadas à sustentabilidade e à responsabilidade social das empresas. 


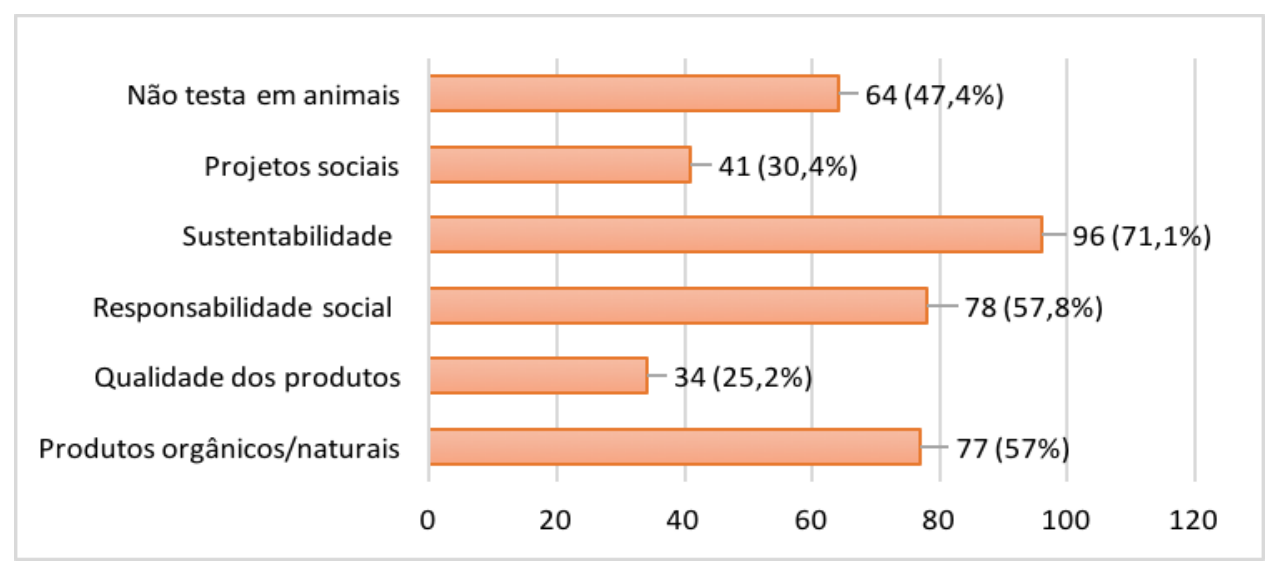

Gráfico 6 - Respostas à pergunta sobre associações a marcas de cosméticos

Foi utilizada na pesquisa uma escala likert para que os respondentes apontassem o quanto iniciativas de sustentabilidade e responsabilidade social são valorizadas por eles. É importante ressaltar que não foram abordadas na pesquisa todas as práticas de sustentabilidade e responsabilidade social feitas pelas marcas de cosméticos, o estudo focou em algumas práticas específicas que foram consideradas como as mais importantes pela autora.

Segundo Nascimento (2012) um produto que tem em sua composição algum material reciclável economizará matéria-prima nova e ainda irá incentivar o mercado de reciclagem. De acordo com o especialista em economia circular e sustentabilidade e coordenador do grupo de resíduos sólidos da Associação Brasileira da Indústria de Máquinas e Equipamentos (Abimaq) Paulo Da Pieve, o país gera aproximadamente 80 milhões de toneladas de despejo por ano e recicla somente $3 \%$. As empresas brasileiras vêm enfrentando este desafio para se tornarem mais sustentáveis. (PIZARRO, 2017).

Ainda segundo Pizarro (2017) o gerente de sustentabilidade da marca de cosméticos Natura, Keyvan Macedo acredita que o consumidor brasileiro está mais cuidadoso no que diz respeito a origem dos materiais e aos modos de produção.

Diante da importância da reciclagem, a primeira assertiva abordada foi: "prefiro cosméticos que utilizam embalagens biodegradáveis ou recicláveis". Como resultado $51,1 \%$ dos consumidores concordam totalmente e preferem adquirir cosméticos que utilizam embalagens biodegradáveis ou recicláveis e $20,7 \%$ concordam parcialmente. $16,3 \%$ não concordam, nem discordam. 3,7\% 
discordam parcialmente e $8,1 \%$ discordam totalmente. Isso mostra que o consumidor está preocupado com o seu consumo e o impacto ao meio ambiente.

Segundo Tachizawa (2015) a tendência de conservação e precaução ambiental por parte das empresas deve seguir permanentemente. Os resultados econômicos das organizações derivam de decisões que considerem que: o movimento ambientalista vem crescendo cada vez mais, em uma proporção global, a preocupação de consumidores e sociedade com a proteção do meio ambiente e a dependência entre o comportamento do consumidor, que preza por produtos e empresas ecologicamente corretas.

De acordo com Nascimento (2012) ao projetar um novo produto deve ser levado em consideração o que será feito com este produto após o fim de sua vida útil. Para recolher o produto após a sua utilização, as empresas devem disponibilizar para os consumidores canais de recolhimento (logística reversa de pós-uso). Após o recolhimento do produto deve ser dado a ele um destino apropriado (reutilização de componentes e reciclagem). Desta forma, a empresa passa a ter uma imagem de ambientalmente correta e responsável.

A segunda assertiva abordada foi: "compro produtos cosméticos que possuem controle de descarte das embalagens". Como resultado $32,1 \%$ dos consumidores concordam totalmente e 14,9\% concordam parcialmente. 29,9\% dos consumidores não concordam, nem discordam. $9 \%$ discordam parcialmente e $14,2 \%$ discordam totalmente. Pode-se observar que o controle do descarte é uma prática de sustentabilidade valorizada pelos consumidores.

Segundo Hawkins, Mothersbaugh e Best (2007) as decisões feitas pelos consumidores em relação à situação de descarte podem gerar problemas sociais, assim como oportunidade para os profissionais de marketing. Alguns consumidores levam em conta a facilidade de descarte no momento de adquirir um item e estes indivíduos podem comprar apenas produtos facilmente recicláveis, desta forma os profissionais devem compreender de que forma as influências situacionais afetam as decisões de descarte, para que possam criar produtos mais éticos.

De acordo com Simões, Ferreira, Afonso e Bartholo (2008) os projetos sociais feitos pelas empresas (promoção da educação, combate ao trabalho infantil, prevenção da criminalidade, combate a exclusão social) são importantes para promover a cidadania e a inclusão social. Algumas empresas desenvolvem projetos sociais muitas vezes administrados por seus próprios institutos e fundações. As empresas devem assimilar que elas se sustentam das forças das pessoas e das comunidades. 
As marcas de cosméticos promovem diversas iniciativas sociais junto da comunidade. O Instituto Natura por exemplo, promove inovações em práticas educacionais, melhoria dos sistemas educacionais e é um agente que mobiliza a sociedade para a educação (NATURA, 2018). O Instituto Grupo Boticário (Eudora, The Beauty Box e quem disse Berenice) promove projetos culturais, esportivos e projetos que estimulam a educação e a saúde (GRUPO O BOTICÁRIO, 2018). O Instituto Avon promove ações de combate ao câncer de mama e a violência doméstica (AVON, 2017). A fundação The Body Shop levanta fundos para luta a favor dos direitos humanos (THE BODY SHOP, 2018). A fundação L'Oréal se compromete com causas sociais nas suas duas áreas de especialização (a ciência e a beleza) a marca é comprometida com a beleza para o benefício dos mais desamparados e a promoção de uma ciência mais acessível (L'ORÉAL BRASIL, 2018). O MAC AIDS Fund (campanha promovida pela MAC Cosmetics) se dedica a combater a relação que existe entre pobreza e HIV/AIDS, oferecendo apoio a instituições que trabalham com populações carentes (MAC COSMETICS, 2018).

Diante da importância dos projetos sociais, a terceira assertiva abordada foi: "identifico-me com empresas cosméticas que desenvolvem projetos sociais junto da comunidade". Como resultado $52,2 \%$ dos consumidores concordam totalmente e 22,4\% concordam parcialmente. 19,4\% não concordam, nem discordam. 3,7\% discordam parcialmente e 2,2\% discordam totalmente. Pode-se perceber que desenvolver projetos sociais é uma iniciativa de sustentabilidade e responsabilidade social valorizada pelos consumidores.

Segundo Nascimento (2012) a apreensão com a conservação do meio ambiente globalizou-se no final da década de 80 , o que permitiu a propagação do conceito de desenvolvimento sustentável. As empresas passaram a adotar e implementar práticas relacionadas a preservação ambiental e a estabelecer políticas de qualidade ambiental na gestão empresarial.

As marcas de cosméticos promovem diversas práticas e ações voltadas para a conservação e preservação da natureza. A Natura por exemplo, lançou em 2011 o programa Amazônia. Em 2016, o programa beneficiou 2.841 mil famílias e contribuiu para a conservação de 257 mil hectares de floresta (NATURA, 2018). O Grupo Boticário promove programas de apoio a iniciativas de conservação da natureza no Brasil, como a preservação de florestas com araucárias, a proteção da biodiversidade e a consolidação de áreas protegidas. (GRUPO O BOTICÁRIO, 2018). A Avon se compromete a proteger o meio ambiente com iniciativas como a redução de emissões de gases do efeito estufa 
e a redução de demandas envolvendo as florestas (AVON, 2017). A The Body Shop promove campanhas em prol do meio ambiente voltadas para o fim das queimas florestais e promoção de energias renováveis. (THE BODY SHOP, 2018). A L'Oréal possui iniciativas para a redução da emissão de gases do efeito estufa e políticas de proteção dos recursos naturais e da biodiversidade (L'ORÉAL BRASIL, 2018). A MAC Cosmetics promove o Back to MAC, premiando os clientes com um produto em troca de embalagens vazias, diminuindo o impacto ambiental (MAC COSMETICS, 2018).

De acordo com Simões, Ferreira, Afonso e Bartholo (2008) para uma empresa ser sustentável do ponto de vista ambiental, ela deve gerar formas de avalição que viabilizem melhores tomadas de decisão e um maior investimento no que diz respeito à proteção ambiental.

Diante da importância de práticas que buscam a conservação e a preservação do meio ambiente, a quarta assertiva abordada foi: "identifico-me com empresas cosméticas que promovem ações pela conservação da natureza". Como resultado $67,9 \%$ dos consumidores concordam totalmente e 11,9\% concordam parcialmente. $15,7 \%$ não concordam, nem discordam. 1,5\% discordam parcialmente e $3 \%$ discordam totalmente. Pode-se observar que o desenvolvimento de iniciativas voltadas para a conservação e preservação do meio ambienta são muito valorizadas pelos consumidores.

A quinta assertiva abordada foi: "busco empresas cosméticas que não realizam testes em animais". Como resultado $56 \%$ dos consumidores concordam totalmente e 10,4\% concordam parcialmente. 20,9\% não concordam, nem discordam. $3 \%$ discordam parcialmente e 9,7\% discordam totalmente. Pode-se observar que grande parte dos consumidores buscam por empresas cosméticas que não testam em animais, isso pode ser uma questão no momento de tomada de decisão.

De acordo com o Projeto Esperança Animal (2017) e o People for the Ethical Treatment of Animals (2017) marcas de cosméticos como a Natura, O Grupo Boticário (Eudora, Quem disse Berenice, The Beauty Box) e The Body Shop não fazem testes em animais. Estas marcas buscam métodos alternativos, incentivando o banimento de testes em animais entre seus fornecedores e parceiros. Segundo Marçal (2015) marcas de cosméticos como MAC Cosmetics, L'Oréal e Avon desenvolveram métodos alternativos ao teste em animais, como testes in vitro (tubo de ensaio/cultura de testes) e a reconstrução de modelos de pele humana em laboratório, contudo, um número pequeno de países ainda exige testes de segurança adicionais (o que pode incluir testes em animais) 
fazendo com que marcas como MAC Cosmetics, L'Oréal e Avon acabem adotando essas medidas.

A última assertiva abordada foi: "antes de comprar um cosmético verifico a sua composição ou seus ingredientes". Como resultado $24,6 \%$ dos consumidores concordam totalmente e $24,6 \%$ concordam parcialmente. $14,9 \%$ não concordam, nem discordam. 12,7\% discordam parcialmente e $23,1 \%$ discordam totalmente. Diante destes resultados, podemos observar que a maioria dos consumidores se importa com a composição e os ingredientes utilizados nos produtos cosméticos. As matérias-primas utilizadas na composição dos cosméticos representam uma questão para os consumidores no momento de decisão de compra. O resumo destes resultados se encontra na Tabela 8

Segundo Kotler e Keller (2012) e Solomon (2016) o consumidor faz julgamento baseado nos benefícios relacionados à escolha do produto e no seu conjunto de atributos. Diante disto e dos resultados do estudo, os consumidores fazem julgamento levando em conta a composição ou ingredientes dos cosméticos sustentáveis, o que está relacionado com os benefícios para a saúde/bem-estar.

Os resultados destas assertivas que buscaram entender o quanto iniciativas de sustentabilidade e responsabilidade social são valorizadas pelos consumidores contradizem os achados de Isaac (2016) que apontam a falta de valor dos consumidores em relação a adoção de práticas de sustentabilidade e de responsabilidade social pelas empresas cosméticas, a extinção dos testes em animais, o uso de embalagens biodegradáveis ou recicláveis e ainda o impacto do produto cosmético no meio ambiente.

Os resultados verificados no estudo de Silva e Bertrand (2009) e Joshi e Rahman (2015) apontam uma atitude positiva do consumidor em relação a aquisição de produtos sustentáveis, porém na prática os consumidores não se comportam desta forma. Ou seja, existe uma preocupação em relação a questão de práticas sustentáveis ou de responsabilidade social, porém a falta de informação foi apontada como a maior barreira para a compra de cosméticos sustentáveis, o que também é verificado no estudo de Vicente, Matsubara e Eiro (2012). Em seu estudo, os autores apontam a necessidade de um maior empenho da indústria cosmética em divulgar mais os atributos sustentáveis de seus produtos. 


\begin{tabular}{|c|c|c|c|c|c|c|c|c|c|c|}
\hline \multicolumn{11}{|c|}{ ESCALA DE LIKERT } \\
\hline Posição & \multicolumn{2}{|c|}{ Concordo totalmente } & \multicolumn{2}{|c|}{ Concordo parcialmente } & \multicolumn{2}{|c|}{ Não concordo, nem discordo } & \multicolumn{2}{|c|}{\begin{tabular}{|l} 
Discordo parcialmente \\
\end{tabular}} & \multicolumn{2}{|c|}{ Discordo totalmente } \\
\hline Assertivas & FREQUENCIA & $\%$ & FREQUENNCIA & $\%$ & FREQUENCIA & $\%$ & FREQUENACIA & $\%$ & \begin{tabular}{|l|} 
FREQUENCIA \\
\end{tabular} & $\%$ \\
\hline $\begin{array}{c}\text { Prefiro cosméticos que utilizam } \\
\text { embalagens biodegradáveis ou } \\
\text { recicláveis }\end{array}$ & 69 & $51,10 \%$ & 28 & $20,70 \%$ & 22 & $16,30 \%$ & 5 & $3,70 \%$ & 11 & $8,10 \%$ \\
\hline $\begin{array}{l}\text { Compro produtos cosméticos } \\
\text { que possuem controle do } \\
\text { descarte das embalagens }\end{array}$ & 43 & $32,10 \%$ & 20 & $14,90 \%$ & 40 & $29,90 \%$ & 12 & $9 \%$ & 19 & $14,20 \%$ \\
\hline $\begin{array}{c}\text { Identifico-me com empresas } \\
\text { cosméticas que desenvolvem } \\
\text { projetos socials junto da } \\
\text { comunidade }\end{array}$ & 70 & $52,20 \%$ & 30 & $22,40 \%$ & 26 & $19,40 \%$ & 5 & $3,70 \%$ & 3 & $22 \%$ \\
\hline $\begin{array}{l}\text { Identifico-me com empresas } \\
\text { cosméticas que promovem } \\
\text { açóes pela conservaçăo da } \\
\text { natureza } \\
\end{array}$ & 91 & $67,90 \%$ & 16 & $11,90 \%$ & 21 & $15,70 \%$ & 2 & $1,50 \%$ & 4 & $3 \%$ \\
\hline $\begin{array}{c}\text { Busco empresas cosméticas } \\
\text { que não realizam testes em } \\
\text { animais }\end{array}$ & 75 & $56 \%$ & 14 & $10,40 \%$ & 28 & $20,90 \%$ & 4 & $3 \%$ & 13 & $9,70 \%$ \\
\hline $\begin{array}{l}\text { Antes de comprar um } \\
\text { cosmético verifico a sua } \\
\text { composiç̄o ou seus } \\
\text { ingredientes }\end{array}$ & 33 & $24,60 \%$ & 33 & $24,60 \%$ & 20 & $14,90 \%$ & 17 & $12,70 \%$ & 31 & $23,10 \%$ \\
\hline
\end{tabular}

Figura 2 - Respostas às assertivas sobre iniciativas de sustentabilidade

\subsection{Motivações e barreiras para a compra de cosméticos sustentáveis}

De acordo com Hawkins, Mothersbaugh e Best (2007) a motivação é a causa do comportamento. Um motivo surge através de uma força interna do consumidor que o estimula e se traduz em uma resposta comportamental, fazendo-o agir de uma certa maneira. Tanto as necessidades quanto os motivos induzem o que os consumidores entendem e compreendem como pertinente e também instigam suas emoções e sentimentos.

Os respondentes foram questionados quanto às suas motivações para a compra de cosméticos sustentáveis. O objetivo desta pergunta foi entender melhor o perfil dos consumidores de cosméticos sustentáveis. Como resultado $80,9 \%$ procuram por cosméticos sustentáveis pela preocupação com o meio ambiente e $46,8 \%$ se preocupam com o futuro do planeta/novas gerações. $57,4 \%$ são motivados pelos seus valores pessoais e $61,7 \%$ se preocupam com a saúde e o bem-estar. 34\% compram pela qualidade dos produtos sustentáveis. As três principais motivações são: a preocupação com o meio ambiente, saúde e bem-estar e os valores pessoais dos consumidores, conforme se observa no Gráfico 7. 


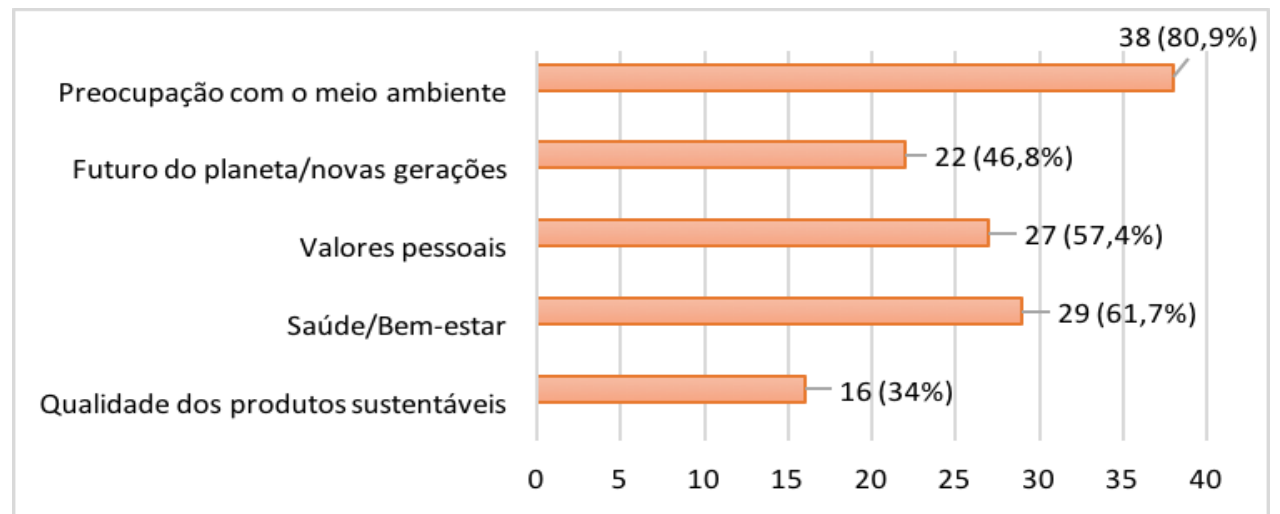

Gráfico 7 - Respostas à pergunta sobre motivos para a compra sustentável

Estes resultados reforçam os achados de Vicente, Matsubara e Eiro (2012) que apontam como fatores de maior influência na decisão de aquisição de cosméticos sustentáveis a preocupação do consumidor com o meio ambiente, o futuro do planeta e seus valores pessoais. Os resultados verificados no estudo de Isaac (2016) apontam a convicção de que os cosméticos são mais benéficos para a pele e para a saúde como o principal fator que afeta a decisão de compra do consumidor.

Segundo Churchill e Peter (2012) e Solomon (2016) as necessidades utilitárias se baseiam nas funções básicas, primárias e nos benefícios percebidos, o consumidor inclina-se a ter um comportamento mais racional. Esta teoria reforça os achados do estudo, uma vez que os consumidores são motivados principalmente pela preocupação com o meio ambiente, saúde/bemestar e seus valores pessoais, sendo estas necessidades utilitárias.

Para entender o perfil dos 88 consumidores que não procuram por cosméticos sustentáveis no momento da compra, eles foram questionados sobre as barreiras que os impedem de adquirir este tipo de produto. Como resultado $60,2 \%$ alegam que é por falta de informação e 18,2\% não pensam sobre 0 assunto. $35,2 \%$ não conseguem diferenciar um cosmético convencional de um sustentável e $25 \%$ consideram o preço elevado, apenas $6,8 \%$ têm falta de confiança em produtos verdes. As três principais barreiras são: falta de informação, não conseguir diferenciar um cosmético convencional de um sustentável e o preço elevado, conforme se observa no Gráfico 8. 


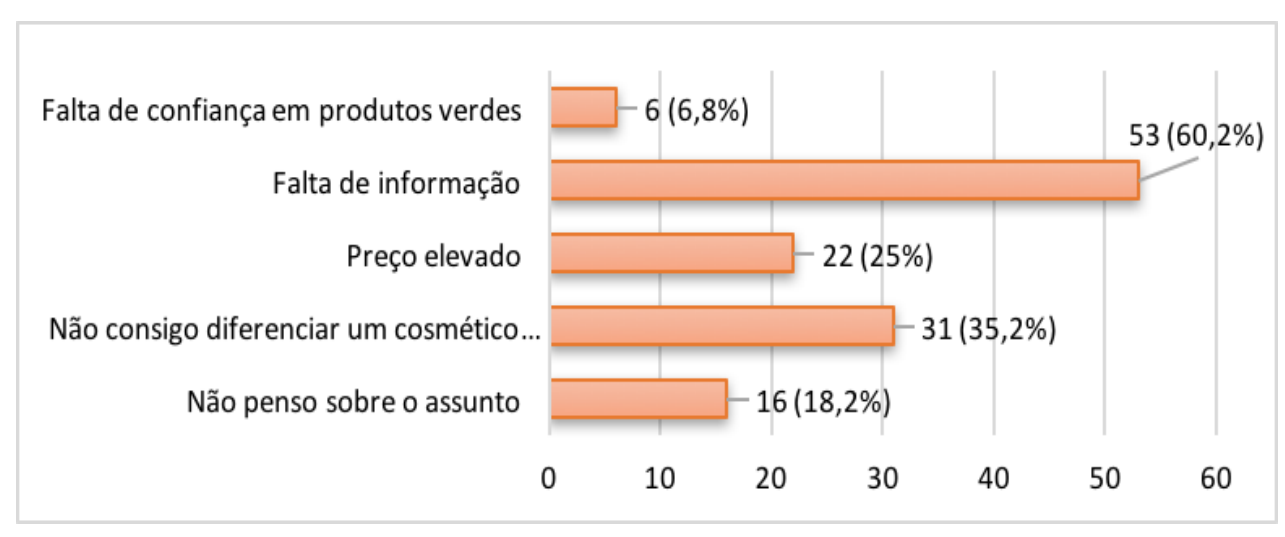

Gráfico 8 - Respostas à pergunta sobre barreiras a compra sustentável

Estes resultados reforçam os achados de Vicente, Matsubara e Eiro (2012) que apontam como barreiras na decisão de aquisição de cosméticos sustentáveis o fato dos consumidores não conseguirem diferenciar um cosmético convencional de um sustentável e a falta de informação a respeito destes produtos. Os resultados verificados no estudo de Isaac (2016) apontam o preço elevado como uma barreira e um limitador no processo de compra, contudo os resultados da atual pesquisa mostram que os consumidores estão dispostos a pagar um pouco mais por produtos cosméticos fabricados de forma sustentável. 


\section{Conclusão}

O presente estudo teve por objetivo entender melhor e averiguar a influência da sustentabilidade na decisão de compra dos consumidores por produtos cosméticos. Para tal, buscou-se compreender se iniciativas de sustentabilidade do referido setor são valorizadas pelos consumidores e identificar os motivos que levam os consumidores a comprarem produtos sustentáveis. Também investigou-se os fatores que podem ser barreiras que influenciem negativamente os consumidores na compra de produtos cosméticos.

A preocupação com o meio ambiente, a saúde e o bem-estar e os valores pessoais foram os fatores de maior influência na decisão de aquisição de cosméticos sustentáveis. A falta de informação, o fato dos consumidores não conseguirem diferenciar um cosmético convencional de um cosmético sustentável e o preço elevado foram as barreiras e principais fatores que podem influenciar negativamente os consumidores na compra de cosméticos sustentáveis.

Apesar do preço elevado ter sido apontado como uma barreira na aquisição de cosméticos sustentáveis, os resultados do presente estudo mostraram que grande parte dos consumidores estão dispostos a pagar um pouco mais por produtos cosméticos fabricados de forma sustentável e têm o costume de verificar se o cosmético agride o meio ambiente além de buscarem informações de novos produtos que se apresentem como sustentáveis.

Quanto à valorização do consumidor em relação às práticas e iniciativas de sustentabilidade do setor de cosméticos, a maioria dos consumidores mostrou que tem interesse e que valoriza estas práticas, como a utilização de embalagens biodegradáveis ou recicláveis, o controle do descarte das embalagens, o desenvolvimento de projetos sociais junto da comunidade, promoções de ações pela conservação da natureza, não realização de testes em animais e os ingredientes utilizados na composição dos cosméticos.

O estudo mostrou que ter a opção de um cosmético sustentável influencia na decisão de compra da maioria dos consumidores, contudo no momento de compra a maioria não procura por cosméticos sustentáveis. Pode-se observar uma discrepância no resultado destas duas questões. Os consumidores 
possuem uma atitude favorável a produtos sustentáveis, uma vez que a maior parte deles é influenciado por cosméticos sustentáveis, contudo essa influência não se traduz na prática da compra, já que a maioria não apontou esse mesmo resultado no momento da compra. Esse resultado leva a uma suposição de que, embora os consumidores não considerem os cosméticos sustentáveis como primeira opção de compra, caso uma opção sustentável seja apresentada, o consumidor irá ponderar e considerar esta opção no momento da tomada de decisão.

Diante dos resultados do estudo realizado pode-se observar que os consumidores valorizam as questões relacionadas à sustentabilidade e responsabilidade social, porém ainda não é um grande fator decisivo no momento de compra, não se traduzindo dessa forma na compra de produtos cosméticos sustentáveis. Um dos motivos para este resultado pode ser a falta de informação por parte das empresas em relação a seus produtos, tendo sido apontada pelos consumidores como a maior barreira para a compra de cosméticos sustentáveis.

A sustentabilidade influencia os consumidores, contudo foi observado no estudo que não é o único fator de decisão de compra. Os consumidores ainda são muito influenciados principalmente pela qualidade dos produtos cosméticos e pelo seu preço e valor final. Grande parte dos respondentes se mostraram dispostos a pagar um pouco mais por produtos cosméticos fabricados de forma sustentável, entretanto o preço elevado foi apontado como uma barreira. Muitos consumidores podem não estar predispostos a pagar um valor um pouco mais elevado se comparado aos cosméticos convencionais, levando-os a não adquirir cosméticos sustentáveis.

Apesar da sustentabilidade ser um assunto disseminado na atualidade e a maior parte dos consumidores se preocuparem com questões relacionadas ao meio ambiente, o presente estudo sugere que o mercado de cosméticos tem lacunas em sua comunicação com o consumidor consciente. Apesar de algumas marcas de cosméticos promoverem ações em relação ao tema, parece existir maior necessidade de divulgação, comunicação e informação em relação aos atributos e benefícios sustentáveis de seus produtos, uma vez que ainda não é um critério e fator decisivo no momento de compra. 


\subsection{Sugestões e recomendações para novos estudos}

Este estudo se limitou a averiguar algumas iniciativas de sustentabilidade e responsabilidade social feitas pelas marcas de cosméticos, focando em práticas específicas consideradas como as mais importantes pela autora. Uma sugestão para estudos futuros relacionados ao tema é explorar outras ações e práticas de sustentabilidade feitas pelas marcas de cosméticos, que não foram apresentadas no presente estudo. Desta forma será possível ter um melhor resultado em relação às iniciativas sustentáveis e o quanto os consumidores as valorizam.

Outra sugestão para futuras pesquisas é levar em conta outros fatores relacionados à sustentabilidade no setor de cosméticos, como procurar entender melhor e explorar o processo de decisão do consumidor para aquisição de cosméticos sustentáveis e explorar os benefícios dos cosméticos sustentáveis tanto para o meio ambiente quanto para o consumidor. Também é sugerido que seja feita uma pesquisa qualitativa que explore mais profundamente os motivos pelos quais consumidores que se dizem influenciados pela sustentabilidade não efetivamente realizem a compra.

Como recomendação seria interessante que estudos futuros sobre a sustentabilidade e o setor de cosméticos, utilizassem e levassem em conta outras regiões do Brasil, uma vez que a amostra do presente estudo foi majoritariamente de residentes do Rio de Janeiro.

Espera-se que este trabalho incentive mais pesquisas futuras sobre a influência da sustentabilidade no setor de cosméticos e também em relação a outros setores. 


\section{Referências Bibliográficas}

ARCOS, I. S. V.; MATOS, B. V. C.; DUTRA, M. C. P. M.; LIMA, E. V. Empresas verdes: o consumidor frente as novas práticas sustentáveis no mercado de detergente de roupa. Anais do 35 ENEGEP. Fortaleza: Encontro Nacional De Engenharia De Produção, 2015.

Avon. Responsabilidade social. São Paulo, 2018. Disponível em: <http://www.avon.com.br/aavon/responsabilidade-social>. Acesso em: 15 mai. 2018 .

CERQUEIRA, A. C. Comportamento do consumidor de cosméticos: um estudo exploratório. Revista Formadores: Vivências e Estudos, v. 6, n. 1, p.128-157, 2013.

CHURCHILL J. G. A.; PETER, J. P. Marketing criando valor para os clientes. São Paulo: Saraiva, 2012.

CRESWELL, J. W. Projeto de pesquisa: métodos qualitativo, quantitativo e misto. Porto Alegre: Artmed, 2007.

FONSECA, M. R.; ROCHA, T. V.; SPERS, E. E. A influência da responsabilidade social corporativa na imagem de marca: um estudo em empresas brasileiras do setor de cosméticos. Revista Brasileira de Marketing, v. 13, n. 6, p.34-46, 2014.

G1. Salário mínimo em 2018: veja o valor. Rio de Janeiro, 4 jan. 2018. Disponível em: <https://g1.globo.com/economia/noticia/salario-minimo-em-2018veja-o-valor.ghtml>. Acesso em: 5 maio 2018.

Grupo $O$ Boticário. Fundação grupo boticário de proteção à natureza. Curitiba, 2018. Disponível em: <http://www.fundacaogrupoboticario.org.br/pt/oque-fazemos/estacao-natureza/pages/default.aspx>. Acesso em: 15 mai. 2018.

HAWKINS, D. I.; MOTHERSBAUGH, D. L.; BEST, R. J. Comportamento do consumidor construindo a estratégia de marketing. Rio de Janeiro: Elsevier, 2007.

HOUSTON, M. J.; ROTHSCHILD, M. L. A paradigm for research on consumer involvement. 1977. Research Gate, Berlim, 14 jun. 2016. Disponível em: $<$ https://www.researchgate.net/publication/244975333>. Acesso em: 29 abr. 2018.

Instituto Brasileiro de Defesa da Natureza. Consumidores dão preferência para empresas sustentáveis. Rio de Janeiro, 2017. Disponível em: $<$ http://www.ibdn.org.br/2017/07/12/consumidores-dao-preferencia-paraempresas-sustentaveis/>. Acesso em: 30 mar. 2018. 
ISAAC, G. E. A. O desenvolvimento sustentável do setor cosmético e o comportamento do consumidor frente aos cosméticos sustentáveis. São João da Boa Vista, 2016. 140 p. Dissertação (Mestrado em Educação, Ambiente e Sociedade) - Centro Universitário das Faculdades Associadas de Ensino.

JOSHI, Y.; RAHMAN, Z. Factors affecting green purchase behaviour and future research directions. International Strategic Management Review. v. 3, n. 1-2, p.128-143, 2015.

KOTLER, P.; KELLER, K. L. Administração de marketing. São Paulo: Pearson, 2012.

L'Oréal Brasil. Ciência e beleza. Rio de Janeiro, 2018. Disponível em: <http://www.loreal.com.br/responsabilidade-corporativa/a-fundação-l'oréal>. Acesso em: 15 maio 2018.

L'Oréal Brasil. Um esforço ambiental conjunto. Rio de Janeiro, 2018. Disponível em: <http://www.loreal.com.br/fornecedores/nossa-política-decompras-sustentáveis/um-esforço-ambiental-conjunto>. Acesso em: 15 maio 2018.

Mac Cosmetics. Back to Mac. São Paulo, 2018. Disponível em: <https://www.maccosmetics.com.br/back-to-mac>. Acesso em: 15 maio 2018.

Mac Cosmetics. Viva Glam e o Mac Aids Fund. São Paulo, 2018. Disponível em: <https://www.maccosmetics.com.br/viva-glam-m·a.c-aids-fund-product-macaids-fund-page>. Acesso em: 15 maio 2018.

MARÇAL, G. Maioria de empresas de cosméticos ainda faz testes em animais. 2015. O Estado de S. Paulo, São Paulo, 17 dez. 2015. Disponível em: $<$ https://emais.estadao.com.br/noticias/moda-e-beleza,maioria-de-empresas-decosmeticos-ainda-faz-testes-em-animais,10000005130>. Acesso em: 5 maio 2018.

NASCIMENTO, L. F. Gestão ambiental e sustentabilidade. Florianópolis: Ufsc, 2012.

Natura. Instituto Natura nossas iniciativas. São Paulo, 2018. Disponível em: <http://www.institutonatura.org.br/iniciativa/>. Acesso em: 15 maio 2018.

Natura. Floresta viva Amazônia, biocomércio ético e inclusão social. São Paulo, 2018. Disponível em: <http://www.natura.com.br/sustentabilidade/florestaviva>. Acesso em: 15 mai. 2018.

O ESTADO DE SÃO PAULO. A beleza da sustentabilidade: indústria de cosméticos se reformula para produzir de maneira mais verde. São Paulo, 29 jan. 2018. Disponível em: <https://economia.estadao.com.br/blogs/ecoando/abeleza-da-sustentabilidade-industria-de-cosmeticos-se-reformula-para-produzirde-maneira-mais-verde/>. Acesso em: 31 mar. 2018.

OLIVEIRA, F. C.; GUIMARÃES, F. P. M. Responsabilidade social das empresas e sua relevância para a evolução social na perspectiva da realidade brasileira. Revista Brasileira de Direito Empresarial, v. 3, n. 2, p.100-115, 2017. 
OLIVEIRA, L. P. B. A.; MELO, C. R.; PRADO, M. L.; BRUGGEMANN, O. M. Potencialidades e limites das abordagens de pesquisa qualitativa e quantitativa. Anais do $17^{\circ}$ Senpe. Natal: Seminário Nacional De Pesquisa Em Enfermagem, 2013.

OLIVEIRA, P. Bem-estar: cresce a busca por cosméticos orgânicos e naturais. Mundo do marketing, Rio de Janeiro, 31 mar. 2015. Disponível em: $<$ https://www.mundodomarketing.com.br/reportagens/mercado/33217/bem-estarcresce-a-busca-por-cosmeticos-organicos-e-naturais.html>. Acesso em: 5 maio 2018.

People For The Ethical Treatment Of Animals. Search for cruelty-free cosmetics, personal care products and more. Virgínia, 2017. Disponível em: $<$ http://features.peta.org/cruelty-free-company-search/index.aspx>. Acesso em: 15 maio 2018.

PIVA, N. Socióloga sai da Amazônia para Curitiba com uma certeza: vender cosméticos orgânicos é um bom negócio. Gazeta do Povo, Curitiba, 29 mar. 2017. Disponível em: <http://www.gazetadopovo.com.br/economia/empreenderpme/sociologa-sai-da-amazonia-para-curitiba-com-uma-certeza-vender-

cosmeticos-organicos-e-um-bom-negocio-1ergwp67yzzolr5t1v2gbgox0>. Acesso em: 05 mai. 2018.

PIZARRO, L. Brasil perde $\mathbf{R} \$ \mathbf{1 2 0}$ bilhões por ano ao não reciclar lixo. $\mathrm{O}$ Tempo, Minas Gerais, 16 jan. 2017. Disponível em: <https://www.otempo.com.br/capa/economia/brasil-perde-r-120-bilh\%c3\%b5espor-ano-ao-n\%c3\%a3o-reciclar-lixo-1.1423628>. Acesso em: 15 mai. 2018.

PRATA, M. O mercado dos cosméticos sustentáveis. 2017. O Globo, Rio de Janeiro, 13 nov. 2017. Disponível em: <http://g1.globo.com/globo-news/mundosa/videos/v/mundo-sa-o-mercado-dos-cosmeticos-sustentaveis/6287186/>.

Acesso em: 31 mar. 2018.

PRODANOV, C. C.; FREITAS, E. C. Metodologia do trabalho científico: métodos e técnicas da pesquisa e do trabalho acadêmico. Novo Hamburgo: Feevale, 2013.

Projeto Esperança Animal. Empresas que não testam em animais. São Paulo, 2017. Disponível em: <http://www.pea.org.br/crueldade/testes/naotestam.htm>. Acesso em: 15 maio 2018.

SANTOS, B. F. Consumidores querem empresas preocupadas com o meio ambiente. 2017. Veja, São Paulo, 17 jan. 2017. Disponível em: $<$ https://veja.abril.com.br/economia/consumidores-querem-empresaspreocupadas-com-o-meio-ambiente/>. Acesso em: 31 mar. 2018.

SILVA, D. R. Sustentabilidade empresarial como estratégia competitiva: análise de empresas brasileiras classificadas como mais sustentáveis em 2016. Cacoal, 2017. 39 p. TCC (Graduação em Ciências Contábeis) - Fundação Universidade Federal de Rondônia. 
SILVA, R. C. M.; BERTRAND, H. O comportamento socialmente responsável das empresas influencia a decisão de compra do consumidor? Pensamento Contemporâneo em Administração, v. 3, n. 1, p.10-25, 2009.

SILVA, R. M.; FERNANDES, R. A. A inserção das questões sociais e ambientais nas estratégias organizacionais: relato de ações adotadas por empresas do setor de cosméticos no Brasil. Unoesc \& Ciência - Acsa, v. 7, n. 1, p.15-24, 2016.

SIMÕES, C. P.; FERREIRA, G. S.; AFONSO, R. C. M.; BARTHOLO, R. Responsabilidade social e cidadania conceitos e ferramentas. Brasília: Sesi, 2008.

SOLOMON, M. R. O comportamento do consumidor comprando, possuindo e sendo. Porto Alegre: Bookman, 2016.

SOUZA, C. L. M. V. A problemática dos métodos quantitativos e qualitativos em biblioteconomia e documentação: uma revisão de literatura. Ciência da Informação, v. 18, n. 2, p.174-182, 1989.

TACHIZAWA, T. Gestão ambiental e responsabilidade social corporativa estratégias de negócios focadas na realidade brasileira. São Paulo: Atlas, 2015.

The Body Shop. Nossas campanhas. São Paulo, 2018 Disponível em: <https://www.thebodyshop.com.br/p/campanhas>. Acesso em: 15 maio 2018.

VICENTE, N. A.; MATSUBARA, R. Y.; EIRO, N. Y. Estratégia e sustentabilidade a influência da sustentabilidade na compra de cosméticos. Anais do XV SemeAd. São Paulo: Seminários em Administração da Universidade de São Paulo, 2012.

ZIKMUND, W. G.; BABIN, B. J. Princípios da pesquisa de marketing. São Paulo: Cengage Learning, 2012. 


\section{Anexo 1}

\section{Questionário}

Esta pesquisa tem 0 intuito de analisar e avaliar $o$ quanto fatores relacionados a sustentabilidade no setor de cosméticos (perfumes, cremes para pele/rosto, maquiagem) afetam a decisão de compra dos consumidores. Em seguida são apresentadas as perguntas do questionário respondido pelos participantes da pesquisa.

1) Você compra cosméticos? (perfumes, cremes para pele/rosto, maquiagem)
( ) Sim
( ) Não

2) Sexo
( ) Feminino
( ) Masculino

3) Faixa etária
( ) De 15 a 20 anos
( ) De 21 a 30 anos
( ) De 31 a 40 anos
( ) De 41 a 50 anos
( ) Acima de 50 anos

4) Renda familiar
( ) Até 1 salário mínimo
( ) De 1 a 3 salários mínimos
( ) De 4 a 10 salários mínimos
( ) Mais de 10 salários mínimos

5) Escolaridade 

( ) Ensino fundamental completo
( ) Ensino fundamental incompleto
( ) Ensino médio completo
( ) Ensino médio incompleto
( ) Superior completo
( ) Superior incompleto

\section{6) Ocupação}
( ) Estudante
( ) Funcionário de empresa privada
( ) Funcionário de empresa pública

7) Quais são as principais formas de intermediação comercial que você utiliza ao comprar cosméticos?
( ) Consultora
( ) Farmácia
( ) Perfumaria
( ) Loja própria
( ) Supermercado
( ) Internet
( ) Lojas especializadas
( ) Outros

8) Quais marcas você costuma comprar?
( ) Avon
( ) Natura
( ) O Boticário
( ) Eudora
( ) The Beauty Box
( ) Quem disse Berenice
( ) The Body Shop
( ) MAC
( ) L'Oréal
( ) Outras

9) Quais são os seus critérios de seleção dessa marca?
( ) Imagem da marca 

( ) Indicação de terceiros
( ) Preço
( ) Facilidade de compra
( ) Qualidade do produtos
( ) Critério de proteção ambiental/preservação do meio ambiente
( ) Outros

10) Entre as marcas abaixo, quais você associa a sustentabilidade?
( ) Avon
( ) Natura
( ) O Boticário
( ) Eudora
( ) The Beauty Box
( ) Quem disse Berenice
( ) The Body Shop
( ) MAC
( ) L'Oréal
( ) Outras

11) Qual é o seu interesse por assuntos relacionados a sustentabilidade?
( ) Muito interesse
( ) Pouco interesse
( ) Nenhum interesse

12) Ter a opção de um cosmético sustentável influencia na sua decisão de compra?
( ) Sim
( ) Não

13) Você já utilizou ou utiliza um cosmético orgânico ou natural?
( ) Sim
( ) Não

14) No momento de compra de cosméticos você procura por cosméticos sustentáveis?
( ) Sim 
( ) Não

15) Quais motivos te levam a isso?

( ) Preocupação com o meio ambiente

( ) Futuro do planeta/novas gerações

( ) Valores pessoais

( ) Saúde/Bem-estar

( ) Qualidade dos produtos sustentáveis

( ) Outros

16) Quais motivos te levam a isso?

( ) Não penso sobre o assunto

( ) Preço elevado

( ) Falta de informação

( ) Falta de confiança em produtos verdes

( ) Não consigo diferenciar cosméticos convencionais de sustentáveis

17) O que você associa a marcas de cosméticos sustentáveis?
( ) Produtos orgânicos/naturais
( ) Qualidade dos produtos
( ) Responsabilidade social
( ) Sustentabilidade
( ) Projetos sociais
( ) Não faz testes em animais
( ) Outros

18) Tenho o costume de verificar se o cosmético agride o meio ambiente
( ) Concordo totalmente
( ) Concordo parcialmente
( ) Não concordo, nem discordo
( ) Discordo parcialmente
( ) Discordo totalmente

19) Busco informações de novos produtos que não sejam nocivos ao meio ambiente
( ) Concordo totalmente 

( ) Concordo parcialmente
( ) Não concordo, nem discordo
( ) Discordo parcialmente
( ) Discordo totalmente

20) Prefiro cosméticos que utilizam embalagens biodegradáveis ou recicláveis
( ) Concordo totalmente
( ) Concordo parcialmente
( ) Não concordo, nem discordo
( ) Discordo parcialmente
( ) Discordo totalmente

21) Compro produtos cosméticos que possuem controle do descarte das embalagens
( ) Concordo totalmente
( ) Concordo parcialmente
( ) Não concordo, nem discordo
( ) Discordo parcialmente
( ) Discordo totalmente

22) Estou disposta a pagar um pouco mais por produtos cosméticos fabricados de forma sustentável
( ) Concordo totalmente
( ) Concordo parcialmente
( ) Não concordo, nem discordo
( ) Discordo parcialmente
( ) Discordo totalmente

23) Identifico-me com empresas cosméticas que desenvolvem projetos sociais junto da comunidade
( ) Concordo totalmente
( ) Concordo parcialmente
( ) Não concordo, nem discordo
( ) Discordo parcialmente
( ) Discordo totalmente 
24) Identifico-me com empresas cosméticas que promovem ações pela conservação da natureza
( ) Concordo totalmente
( ) Concordo parcialmente
( ) Não concordo, nem discordo
( ) Discordo parcialmente
( ) Discordo totalmente

25) Busco empresas cosméticas que não realizam testes em animais
( ) Concordo totalmente
( ) Concordo parcialmente
( ) Não concordo, nem discordo
( ) Discordo parcialmente
( ) Discordo totalmente

26) No momento de compra de um cosmético, tenho facilidade em distinguir um produto cosmético natural/orgânico dos demais
( ) Concordo totalmente
( ) Concordo parcialmente
( ) Não concordo, nem discordo
( ) Discordo parcialmente
( ) Discordo totalmente

27) Antes de comprar um cosmético verifico a sua composição ou seus ingredientes
( ) Concordo totalmente
( ) Concordo parcialmente
( ) Não concordo, nem discordo
( ) Discordo parcialmente
( ) Discordo totalmente 